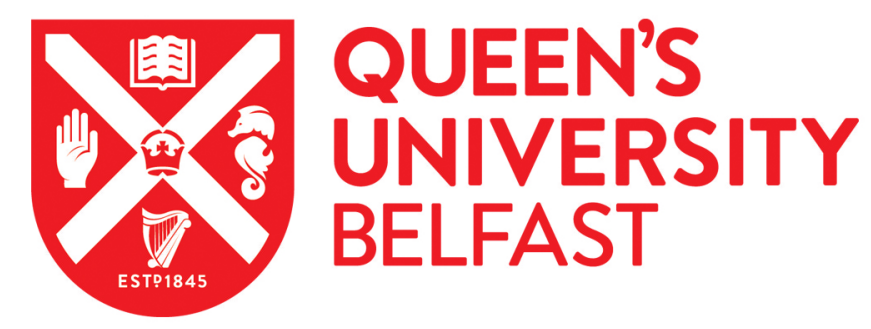

\title{
Modelling the nonlinear behaviour and fracture process of AS4/PEKK thermoplastic composite under shear loading
}

Tan, W., \& Falzon, B. (2016). Modelling the nonlinear behaviour and fracture process of AS4/PEKK thermoplastic composite under shear loading. Composites Science and Technology, 126, 60-77. https://doi.org/10.1016/j.compscitech.2016.02.008

\section{Published in:}

Composites Science and Technology

\section{Document Version:}

Peer reviewed version

Queen's University Belfast - Research Portal:

Link to publication record in Queen's University Belfast Research Portal

Publisher rights

(C) 2016, Elsevier

This manuscript version is made available under the CC-BY-NC-ND 4.0 license http://creativecommons.org/licenses/by-nc-nd/4.0/ which permits distribution and reproduction for non-commercial purposes, provided the author and source are cited.

\section{General rights}

Copyright for the publications made accessible via the Queen's University Belfast Research Portal is retained by the author(s) and / or other copyright owners and it is a condition of accessing these publications that users recognise and abide by the legal requirements associated with these rights.

Take down policy

The Research Portal is Queen's institutional repository that provides access to Queen's research output. Every effort has been made to ensure that content in the Research Portal does not infringe any person's rights, or applicable UK laws. If you discover content in the Research Portal that you believe breaches copyright or violates any law, please contact openaccess@qub.ac.uk. 


\title{
Modelling the nonlinear behaviour and fracture process of AS4/PEKK thermoplastic
}

\section{composite under shear loading}

\author{
Wei Tana,b, Brian G. Falzonb, ${ }^{*}$ \\ a School of Mechanical and Electrical Engineering, Central South University, Changsha, 410083, China \\ b School of Mechanical and Aerospace Engineering, Queen's University Belfast, Belfast, BT9 5AH, UK \\ *Corresponding author: b.falzon@qub.ac.uk (B.G. Falzon) Tel: +44 (0)28 90975640
}

\begin{abstract}
The accurate determination of non-linear shear behaviour and fracture toughness of continuous carbonfibre/polymer composites remains a considerable challenge. These measurements are often necessary to generate material parameters for advanced computational damage models. In particular, there is a dearth of detailed shear fracture toughness characterisation for thermoplastic composites which are increasingly generating renewed interest within the aerospace and automotive sectors. In this work, carbon fibre (AS4)/ thermoplastic Polyetherketoneketone (PEKK) composite V-notched cross-ply specimens were manufactured to investigate their non-linear response under pure shear loading. Both monotonic and cyclic loading were applied to study the shear modulus degradation and progressive failure. For the first time in the reported literature, we use the essential work of fracture approach to measure the shear fracture toughness of continuous fibre reinforced composite laminates. Excellent geometric similarity in the load-displacement curves was observed for ligament-scaled specimens. The laminate fracture toughness was determined by linear regression, of the specific work of fracture values, to zero ligament thickness, and verified with computational models. The matrix intralaminar fracture toughness (ply level fracture toughness), associated with shear loading was determined by the area method. This paper also details the numerical implementation of a new three-dimensional phenomenological model for carbon fibre thermoplastic composites using the measured values, which is able to accurately represent the full non-linear mechanical
\end{abstract}


response and fracture process. The constitutive model includes a new non-linear shear profile, shear modulus degradation and load reversal. It is combined with a smeared crack model for representing ply-level damage initiation and propagation. The model is shown to accurately predict the constitutive response in terms of permanent plastic strain, degraded modulus as well as load reversal. Predictions are also shown to compare favourably with the evolution of damage leading to final fracture.

Keywords: B. Non-linear behaviour, B. Fracture toughness, C. Damage mechanics, C. Finite element analysis (FEA), Essential work of fracture

\section{Introduction}

The use of carbon-fibre/polymer composite materials in aircraft primary structures can translate to significant benefits in operating costs and performance. With the increasing utilisation of these materials, it is essential to develop a detailed understanding of their response under different loading cases (e.g. tension, compression, shear, impact, etc) to determine design allowables. Under longitudinal loading, the main response of a unidirectional (UD) pre-impregnated composite laminate is controlled by the fibre, exhibiting fibre breakage/pullout in tension and fibre kinking in compression. In contrast, transverse or shear loading may lead to large nonlinear deformation and subsequent matrix cracking, i.e., matrix-dominated failure. The response of a UD ply under shear loading is characterised by nonlinear deformation and shear-induced failure may significantly limit the load-bearing capacity of composite structures, e.g. bolted composite joints $[1,2]$, where the accumulation of bearing damage leads to shear-out cracks. The morphology of composite damage, arising from impact or crush loading, has also been shown to be a function of the material's shear characteristics [3-5].

One of the main difficulties in measuring the shear properties of these materials is in generating a pure shear stress state in the gauge section of a test specimen. This is of particular concern in composites because they exhibit high anisotropy and structural heterogeneity. In general, the ideal shear test must be simple enough to perform, require small and easily fabricated specimens and enable the measurement of reproducible values for 
both shear modulus and shear strength. The V-Notched Rail shear test method (ASTM standard D7078/D7078M12) [6] is essentially a combination of the best features of two commonly used methods, the losipescu Shear [7] and the Two-Rail Shear test methods [8], generating a relatively uniform shear stress state within a larger gauge section between the V-notches as well as eliminating edge crushing and the need of multiple loading holes.

In addition to the characterization of non-linear shear behaviour, the efficient design of composite structures relies heavily on the accurate prediction methods for the initiation and propagation of damage. There are several fracture energy-based approaches to model damage propagation such as the smeared crack band model $[9,10]$, the use of cohesive elements [11] and X-FEM [12], which have been applied across scales [13]. All of these methods require the determination of fracture toughness values, accounting for the overall dissipated energy in the fracture or softening process [14-17].

Round robin testing has seen the emergence of standards for the measurement of Mode I, II and mixed-mode interlaminar fracture toughness values [18]. For intralaminar fracture toughness, compact tension and compact compression $[19,20]$ tests have been widely adopted to measure the toughness associated with longitudinal tensile and compressive failure, respectively. Catalanotti et al. [21, 22] presented size-effect methods to measure the resistance curves (R-curves) for tensile and compressive fracture toughness. However, very few approaches have been presented, in the literature, on fracture toughness associated with shear loading. Catalanotti and Xavier [23] developed a modified cracked losipescu shear test, based on a similar size effect law presented by Bazant [24], to measure the mode II intralaminar fracture toughness and R-curves of fibre reinforced composites based. They overcame the size limitation of the losipescu test fixture by scaling the gauge section of the specimens. A fairly uniform fracture surface was observed and plane-strain fracture was achieved. This method is reliable when elastic behaviour dominates under shear loading. The obtained 'ideal' R-curve was based on linear elastic fracture mechanics. The rising part of the R-curve may significantly change when large plastic deformation is present. In addition, the maximum crack propagation obtained is limited by the gauge section of the specimen to around 
$10 \mathrm{~mm}$. For materials that exhibit a very large ligament of fracture process zone, the size effect obtained using this methodology may not be reliable. In this case the specimen should be scaled and a different test method should be proposed. In the current work, the fracture toughness of composite laminates used for shear testing, was assessed using the essential work of fracture (EWF). EWF is a relatively new concept for determining the energy consumption which aims to extract the energy of crack surface formation from the overall energy dissipated in the yield and fracture process. This method provides an effective means of dealing with gross ductility that can occur in the plane stress fracture state. It has been widely employed to measure the fracture toughness of ductile polymers [25-27], and short fibre reinforced polymers [28]. However, this theory has not been applied to measure the fracture toughness of continuous fibre reinforced composites.

The need for such material characterisation is driven by the impetus towards the development of predictive numerical tools to reduce the extent of physical testing during the development of composite aerostructures. Moreover, such tools can yield further insight into complex damage mechanisms, enabling better exploitation of these materials in aerospace and automotive structures. Composite materials may exhibit significant nonlinearity before failure, particularly with respect to shear deformations. This kind of failure was frequently observed in composite bolted joints manufactured using cross-ply and notched laminates [1, 29], as well as the formation of permanent indentations after impact events $[3,30]$. Therefore, a model dealing with shear non-linearities is required to accurately predict the failure under multiaxial loading states.

To date, two main methodologies have been widely used to model the highly anisotropic behaviour of composite laminates. The first is based on the plasticity theory of anisotropic material using anisotropic flow surface and flow rule $[31,32]$. The other is a physically-based phenomenological failure surface taking into account different failure mechanisms $[33,34]$. Recently proposed models range from detailed micromechanical models, with a discrete representation of the constituents and interfaces, to meso-scale models homogenized at the ply or laminate level for structural analysis. Micro-mechanical analysis models (Totry et al, [35]) with 
appropriate models for the constituents (fibre, matrix and interface) provide detailed information on the actual deformation and fracture process of polymer composites and do not require the simplifying assumptions used in models developed at higher length scales. Although micro-mechanical analysis models are ideal to design the material itself and to understand the effects of defects, such models are currently not suitable for application at a structural level as the link between micro-mechanical and macro-mechanical scales is not well established. Regarding the meso-scale level, Van Paepegem et al. [36, 37] proposed a phenomenological model which introduced shear damage and permanent shear strain as two state variables to model the non-linear shear behaviour. Vogler [38] and Camanho [39] presented a fully three-dimensional transversely isotropic elastic-plastic constitutive model for composite materials to represent the plasticity-based non-linearities under multiaxial loading conditions. This model was coupled with a smeared crack model to simulate the onset and propagation of ply failure. Vyas et al [40] presented a plasticity-based approach to model the nonlinear mechanical response of polymer-matrix fibre-reinforced composites with unidirectional plies under quasi-static loading. However, the interactive damage mechanisms and material non-linearity with degraded shear moduli are not handled well by these models. Loads that induce damage may also cause local unloading, which is not captured by these models. It is therefore essential to continue the work in the understanding and simulation of composite structures under shear loading to mitigate current limitations.

The aim of this study was to characterize the nonlinear behaviour and fracture toughness of a high performance thermoplastic composite, AS4/PEKK, under shear loading and to use this information to develop a high fidelity finite element based damage model. A V-notched rail shear test fixture was employed to apply a pure shear stress state on modified specimens, using gauge section scaling, and determine the in-plane shear fracture toughness based on the essential work of fracture (EWF). A three-dimensional phenomenological model was subsequently implemented in ABAQUS/Explicit as a user subroutine. It is based on $[4,41]$ and is capable of representing the plastic deformation of the matrix as well as the onset and propagation of the ply failure 
mechanisms governed by the in-plane shear fracture toughness, considering the progressive shear modulus degradation, accumulation of permanent plastic strain and isotropic hardening to deal with loading, unloading, reloading and/or load reversal.

\section{Materials and Methods}

\subsection{Materials preparation and test set-up}

The fibre reinforced composite material used in this study was manufactured from unidirectional carbon fibre (AS4D 12K) / poly-ether-ketone-ketone (PEKK) tape provided by Cytec Engineered Materials ${ }^{\circledR}$ with a volume fraction of $60 \%[42]$. Cross-ply $\left[0^{\circ} / 90^{\circ}\right]_{6 s}$, unidirectional $\left[0^{\circ}\right]_{24}$ and $\left[90^{\circ}\right]_{24}$ CF/PEKK composite plates with 24 plies were fabricated using a Collin ${ }^{\circledR}$ heated press. For the consolidation cycle, laminated plates were heated at a constant rate of $15{ }^{\circ} \mathrm{C} / \mathrm{min}$ until $372{ }^{\circ} \mathrm{C}$ and held at this temperature for 30 minutes under 7 bar pressure. Afterwards, the composite plate was cooled to $120^{\circ} \mathrm{C}$ at $2{ }^{\circ} \mathrm{C} /$ min under the same pressure $(7$ bar) which was subsequently released and the composite plate cooled to room temperature in ambient conditions. The nominal thicknesses of the composite plate was measured at $3.36 \pm 0.1 \mathrm{~mm}$. Rectangular specimens $(76 \mathrm{~mm} \times 56 \mathrm{~mm})$ were cut from cross-ply laminates to prepare the shear test specimens. $90^{\circ} \mathrm{V}$-notches with a notch root radius of $1.3 \mathrm{~mm}$ were machined by milling. The $\mathrm{V}$-notched specimens were tested in shear using a screw-driven mechanical testing machine under displacement control at a constant cross-head speed of $1 \mathrm{~mm} / \mathrm{min}$ (Fig. 1a). The applied load was measured continuously with a $50 \mathrm{kN}$ load cell. To ensure a proper grip of the loading fixture to the specimens, the specimen surfaces were roughened using sandpaper.

Biaxial strain gauge rosettes were fixed to the centre of the specimens on the back side to measure the strains $\varepsilon_{+45^{\circ}}$ and $\varepsilon_{-45^{\circ}}$ in the $\pm 45^{\circ}$ direction. The engineering shear strain $\gamma_{12}$ is obtained by $\gamma_{12}=$ $\left|\varepsilon_{+45^{\circ}}\right|+\left|\varepsilon_{-45^{\circ}}\right|$. The average in-plane shear stress, within the ligament, was calculated from the load and the ligament cross sectional area, assuming the effect of stress concentrations at the notches are negligible, $\tau_{12}=$ $F / A=F /(L \times h)$, where $L$ is the ligament length between notches and $h$ is the specimen thickness at the 
notch (Fig. 1b). At the same time, a 3D digital image correlation system (DIC, Dantec ${ }^{\circledR}$ ) was employed to capture the strain field on the other surface of the specimens. The gauge section at the centre of each specimen was sprayed white and speckled with black paint for DIC measurements. Typically, a facet size of $13 \times 13$ pixels is chosen. The stress-strain curves obtained by DIC and strain gauges (SG) matched well until a strain of approximately $8 \%$ was reached (Fig. 1c), beyond which, the strain gauges detached from the specimen. The DIC was able to provide shear strain measurements to $50 \%$ until the initiation of fracture.

\subsection{Optical microscopy and SEM}

Several tests were interrupted at different load levels and plastographic samples were prepared from these specimens to ascertain the progressive development of damage. Sections parallel and perpendicular to the loaded edges were cut and embedded in resin. They were sectioned and polished on SiC paper with 400 to 1200 grit finish, followed by $1 \mu \mathrm{m}$ alumina oxide in preparation of examination under an optical microscope. The fracture surface was also examined using Scanning Electron Microscopy (SEM).

\section{Experimental results}

\subsection{Shear loading on cross-ply laminates}

Fig. 2a shows the load-displacement curves under static and cyclic loading. The loading rates for both static and cyclic tests were $1 \mathrm{~mm} / \mathrm{min}$, while the unloading rate in cyclic tests was $5 \mathrm{~mm} / \mathrm{min}$. Monotonic and cyclic loading curves are coincident up to a displacement of approximately $6 \mathrm{~mm}$. Afterwards cyclic tests show a certain extent of damage recovery in the fracture process (displacement range from $10 \mathrm{~mm}$ to $15 \mathrm{~mm}$ ). The area under the loaddisplacement curve is the total energy dissipated in the overall process. The corresponding in-plane shear stressstrain curves, until final failure, are shown in Fig. 2b. The cross-ply laminate shows initial elastic behaviour, giving a shear modulus of elasticity of $G_{12}=\Delta \tau / \Delta \gamma=5.02 \pm 0.2 \mathrm{GPa}$. The offset in-plane shear strength was determined by translating the shear chord modulus of elasticity line along the strain axis from the origin by $2 \%$ and extending this line until it intersected the stress-strain curve, to give a shear strength of $S_{12}=80.81 \pm$ 
1.5 MPa. The initial linear behaviour was followed by the onset of matrix plastic deformation (developed from $2 \%$ to $10 \%)$. This region was then continued with a strain hardening part, where the hardening rate was practically constant with a linear increase in the material load-bearing capacity. Fibres in this region carried the majority of the axial loads and started to rotate progressively, whilst large matrix deformation was observed to accompany the fibre rotation. The fibres are idealised to act in a scissoring motion, realigning towards the direction of applied stress, allowing further strain to be taken by the laminate. Final fracture was characterised by extensive delamination, matrix cracking and fibre breakage.

Several consecutive loading-unloading cycles were applied to specimens, and considerable permanent shear plastic strain was observed. This inelastic strain is irreversible due to the presence of plasticity and/or extensive matrix cracking. The hysteresis loops presented similar shapes with increasing stress levels after the fibres began to rotate under shear loading. To characterise the stiffness degradation, the in-situ stiffness was defined as the secant shear modulus of each loading-unloading cycle as shown in the Fig. 3a. The relationship between shear modulus and applied shear strain are plotted in Fig. 3b. It can be seen that the shear modulus degraded quickly in the initial matrix yielding regime and then reached a constant level of $2.5 \mathrm{GPa}$ during the fibredominated load bearing process, indicating that the reduced stiffness is mainly associated with matrix plastic deformation. This also confirms that the shear modulus is controlled by matrix deformation and fairly independent of fibre properties, while the linear hardening region relies on the elastic properties of the fibres.

In order to investigate the progressive irreversible damage of the composite material under shear loading, several cyclic tests were performed and unloaded at strains of $18 \%, 34 \%$ and $48 \%$. Polished plastographic sections from the $\gamma=34 \%$ and $\gamma=48 \%$ specimens, parallel to the central notches, were prepared and examined using an optical microscope. Fig. $4 \mathrm{~b}$ shows that there is neither apparent interlaminar nor intralaminar damage when specimens were loaded to an applied strain of $\gamma=34 \%$, during which the stress increases linearly as the fibres rotate and support axial loading. At a strain of $\gamma=48 \%$, in the strain softening region, out- 
of-plane movement of fibre and matrix was shown clearly by comparing section A-A and B-B. This is probably attributed to the several apparent damage modes observed such as matrix cracking, interface debonding, fibre breakage as well as delamination. It is noted that the matrix can experience large plastic deformation without cracking, while the fibre can carry load and maintain overall integrity until the failure strain is reached. The occurrence of extensive matrix plastic deformation suggests a strong fibre/matrix interface bond. In the final stage, the main load drop was caused by fibre pull-out and fibre breakage $(\gamma>50 \%)$.

\subsection{Shear loading on unidirectional laminates}

Experimental tests were also conducted on unidirectional laminates with fibres parallel $\left(\mathrm{V}-90^{\circ}\right)$ or perpendicular $(\mathrm{V}$ $\left.0^{\circ}\right)$ to the applied shear loading direction. Fig. 5 shows the behaviour of unidirectional laminate specimens under different shear loading orientation. $\mathrm{V}-0^{\circ}$ group samples were loaded in a direction perpendicular to the fibres while V- $90^{\circ}$ groups were loaded in a direction parallel to the fibres. The V- $90^{\circ}$ specimens failed at very low strain with a crack propagating through the matrix in the central notch area with little plastic deformation. Fast fracture was triggered by the stress concentration at the notch tip, as expected. Once crack initiated, rapid matrix-dominated failure propagated instantaneously along the fracture plane. The $\mathrm{V}-0^{\circ}$ specimens indicated two sudden load drops at the initiation of the non-linear transition region, which was caused by the appearance of two cracks, propagating from each notch tip and parallel to the fibres. These cracks, along the fibre direction, were generated due to complementary shear stresses in the transverse direction. Details of the failure process can be seen in Fig. 5 , where matrix cracking was the dominant failure mode, accompanied by fibre rotation, fibre pullout and fibre breakage in the final stages. The stress-strain curves of $\mathrm{V}-0^{\circ}$ and $\mathrm{V}-90^{\circ}$ groups were almost identical in the initial part before crack initiation. Subsequent failure modes, following the occurrence of splitting cracks in the $\mathrm{V}-0^{\circ}$ specimens, were not caused by pure shear loading. Consequently, the non-linear behaviour beyond $2 \%$ strain, shown in Fig. 5b, is not necessarily indicative of the shear response. The initiation of cracking in unidirectional laminate specimens, at relatively low loading, suggests that these specimens are not appropriate for the full 
characterisation of the non-linear behaviour of the composite laminate. However, the constitutive response of the ply can be assumed to be the same when shear loading is applied perpendicular or parallel to the fibres without considering the non-linear part in $\mathrm{V}-0^{\circ}$ specimens, beyond $2 \%$ strain, different from the finding of Totry et al. [35]. This assumption is very important when using continuum damage mechanics, where the constitutive response of the ply is the same when sheared perpendicular or parallel to the fibres. Although neither of them were recommended to characterise the non-linear behaviour of composite plies, they provide a good estimate of the mode II matrix shear strength at about 68.4MPa. The mode II intralaminar matrix fracture toughness was obtained using the area method by dividing the total energy by the central notch area to yield a value of $G_{m s}=$ $34.58 \mathrm{~kJ} / \mathrm{m}^{2}$ from $\mathrm{V}-90^{\circ}$ specimens. This value is comparable to the value $34.4 \mathrm{~kJ} / \mathrm{m}^{2}$ measured from Catalanotti and Xavier for IM7/8552 [23] as well as the value $37.87 \mathrm{~kJ} / \mathrm{m}^{2}$ measured by Arkhireyeva and Hashemi [43] for a similar thermoplastic material (pure matrix - PEEK) using essential work of fracture.

\subsection{Fracture toughness measurement}

\subsubsection{Fracture toughness associated with shear loading}

The complex failure modes of material under shear loading make it very challenging to determine the intrinsic laminate-level or ply-level fracture toughness using conventional methods. In this paper, the fracture toughness of composite laminates under shear loading was assessed using the essential work of fracture (EWF). EWF aims to extract the energy of crack surface formation from the overall energy dissipated in the yield and fracture process. This method is particularly appropriate when gross ductility is evident in a plane stress fracture state. EWF is only effective when the ligament part has fully yielded before crack onset and plane stress conditions prevail. With reference to Fig. $1 \mathrm{~b}$, the total work $W_{f}$ can be written as the sum of two terms: (i) the essential work performed in the fracture process zone (FPZ), $W_{e}$, as an area-dependent value, and (ii) the non-essential work consumed in the plastic zone $W_{p}$ which is a volume-related value; $W_{f}=W_{e}+W_{p}=w_{e} L B+\beta w_{p} L^{2}$. Dividing both sides by $L B$, where $B$ is the thickness of the specimen, the specific fracture work is given by $w_{f}=w_{e}+\beta w_{p} L, w_{e}$ and 
$\beta w_{p} L$ are the specific essential work and non-essential work, $\beta$ is a shape factor, and $w_{p}$ is the average plastic work density. Through conducting a series of experiments on V-notched specimens with different ligament lengths, $L, w_{e}$ and $\beta w_{p}$ as the intercept and slope of the $w_{e} v s L$ curve, respectively, can be obtained.

It has been recommended by Cotterell and Reddell [44] that the range of ligament lengths, $L$, be defined by (3 5) $t \leq L \leq 2 r_{p}$, for metals when subjected to the plane-stress. The ligament must be in a state of pure plane stress with fracture occurring after complete yielding of the ligament. This necessary requirement ensures that $w_{e}$, $w_{p}$ and $\beta$ are all independent of the ligament length. This imposes upper and lower limits on the ligament length. The upper limit is determined by the size of the plastic zone, $2 r_{p}=E_{\text {lam }} w_{e} / \pi \sigma_{y}^{2}$, ahead of a crack tip. The lower limit is governed by the thickness, in the order of $3 t$ to $5 t$, where $E_{\text {lam }}$ is the overall laminate stiffness and $\sigma_{y}$ the yield strength. The specimens used in our study are within this range. The obtained value, $w_{e}$, is equivalent to the fracture toughness associated with shear loading, which is a required input parameter for a number of computational damage models [3-5, 45].

\subsubsection{Toughness test setup}

The overall material behaviour under in-plane shear loading consists of matrix yielding, matrix cracking, fibre rotation, fibre breakage, and delamination. In addition, the plane-stress state with large plastic zone made it hard to extract the fracture toughness. Stable crack propagation along the ligament length was not observed either. In this case, classical methods based on linear elastic fracture mechanics (LEFM) to deduce fracture toughness, such as through the area method or compliance method, are not appropriate. To achieve a clear and straight fracture plane with less delamination and intralaminar damage, side grooves were introduced in the ligament area of the specimen to raise the localised stress and facilitate crack growth along that direction. High stiffness steel tabs were used to clamp the specimen and restrict the out-of-plane movement of fibres, as shown in Fig. 6 a. Specimens with six different scaled ligament lengths were tested. Table 1 shows the relevant average geometrical parameters of ligament length $L$ and groove thickness $t$ and corresponding experimental results. Three specimens 
were tested for each geometry, V-0/90-XX, where XX is the percentage of ligament scaling, e.g. 03 represents $30 \%$ of the original ligaments. The failed specimens are shown in Fig. $7 \mathrm{a}$, where the extent of fibre breakage and delamination were observed in proportion to gauge length. The inner sublaminate experienced sliding from the two outer sublaminates, illustrated in Fig. 6b. The load-displacement curves are shown in Fig. 7b. Key images (labelled 1 to 5) are displayed in Fig. 7c to illustrate the overall yield and fracture process for specimen V03. Stage 1 shows full yielding in the ligament region before crack onset. Delamination is shown to initiate from stages 2 to 4 as the fibres rotated and picked up loading under tension, giving rise to the strain hardening behaviour observed in the specimens. In the final stage, sudden fracture occurred with extensive fibre failure. The 'forest' of fibres that had been subjected to mode II loading is observed in Fig. 8a. The 'forest' was a result of the formation of rotated fibres, fibre pull-out and fibre breakage. The development of the fracture process zone (FPZ) and plastic deformation zone occurred across the entire ligament length between the two notches. The fracture process for the grooved V-notched specimens under shear loading is illustrated in Fig. 8b. After the matrix has fully yielded, voids are formed due to extensive matrix cracking, each growing in a direction perpendicular to the maximum principal stresses. As the shear deformation increases, the voids and fibres rotate towards the direction of crosshead movement, while the fibres pick up loading under tension. Finally, fibre pull-out and fibre breakage occurred and gave rise to the fracture surface shown in Fig. 8a.

\subsubsection{Energy calculation}

In order to obtain the fibre-dominated fracture toughness under shear loading, an accurate calculation method is required to distinguish other components (e.g. friction and delamination) contributing to the overall apparent fracture toughness. Based on the energy balance theory, the energy dissipated by different components was classified as total energy, frictional energy and delamination energy. From the area under the load-displacement curves in Fig. 7b, the total energy dissipated was calculated according to $W_{f}=\int P d l$, where $P$ is the applied loading and $l$ is the displacement. 
Since there is relative large movement between the inner and two outer sub-laminates, and large normal clamping forces, the energy dissipated by friction cannot be ignored. The work done by the friction force was approximated as $W_{f r i}=\mu_{k} F_{n} l_{f}$, where $\mu_{k}$ is the friction coefficient, $F_{n}$ is the clamping force and $l_{f}$ is the distance over which the force acts. The friction coefficient was determined according to ASTM D1894 - 14 [46]. Fully separated beams from a double cantilever beam (DCB) sample where used as the base and test laminates. A $2 \mathrm{~kg}$ weight was added on top of the test laminate. The test laminate was pulled by a pulley through a cable connected to an Instron testing machine. Different interfaces of $0 / 0,0 / 45,0 / 90$ and 0/Metal were investigated repeatedly. The average force-time history for each interface is shown in Fig. 9b. The average kinetic friction coefficient of composite-composite and composite-metal was 0.277 and 0.207 respectively. The relationship between applied torque and resulting bolt axial force $F_{b}$ is given by $F_{b}=T / K D$, where $T=55 \mathrm{~N} \cdot \mathrm{m}$ is the applied torque, $K$ is the torque coefficient $(0.2)$ and $D$ is the diameter of the screw $(12 \mathrm{~mm})$, where there are three screws on each side. Therefore, the total force in the normal direction was $3 F_{b}=68.75 \mathrm{kN}$. Assuming that this force was transmitted, by the steel tabs, to the V-notched specimens and distributed uniformly, the normal force, $F_{n}$, acting directly on the delaminated area, $A_{3}$, is given by $F_{n}=3 F_{b} A_{3} / A_{1}$ (Fig. 10a). From the failed specimens (Fig. 8a), $l_{f}$ was measured directly. The combined frictional and fibre tensile force is represented by $F_{R}$ which is parallel to the shear loading direction. The average velocity along the resultant force direction is $\bar{v}=$ $0.5 v_{f}$. Since the friction displacement, associated with sub-laminate rotation under shear loading increases linearly along the fibre direction, the overall frictional energy in one contact surface was calculated from an equivalent displacement of $\bar{v} t=0.5 l_{f}$ where $t$ is the total time. Consequently, the friction energy consumed by one contact surface can be calculated according to $W_{f r i}^{\prime}=0.5 \mu_{k} F_{n} l_{f}$. As there are four contact surfaces, $W_{f r i}=4 W_{f r i}^{\prime}$. The energy dissipated by delamination was determined by multiplying the mode II interlaminar fracture toughness $G_{I I c}$ by the delaminated area, $W_{\text {del }}=4 G_{I I c} A_{3}$. Based on an energy balance, the overall energy necessary to fracture a specimen can be decomposed into two components, $W_{f}=W_{\text {shear }}+W_{p l}$, where 
the fracture energy, $W_{f}=W_{t}-W_{f r i}-W_{d e l}$, and $W_{t}$ is the area under the force-displacement curve. The essential work of fracture for creating new surface in the shear specimens is $W_{\text {shear }}=G_{\text {shear }} L t_{0}$. The nonessential work dissipated due to plastic deformation of the surrounding area is $W_{p l}=\beta G_{p l} L^{2} t_{0}$. As a result, the specific fracture work is given by,

$$
w_{f}=G_{\text {shear }}+G_{p l} \beta L
$$

Typical specific work of fracture, $w_{f}$, versus $L$ plots from V-notched shear tests are shown in Fig. 10b. The critical specific work of fracture under shear loading was determined by linear regression of $w_{f}$ values to zero ligament thickness. The laminate fracture toughness associated with shear loading was obtained as $G_{\text {shear }}=G_{l a m_{\_} s}=$ $576.62 \mathrm{~kJ} / \mathrm{m}^{2}$.

\subsubsection{Fractographic analysis}

Fig. 11a and Fig. 11b show the representative SEM fracture surface images of tested sample V-0/90-03, indicating extensive rotation, pull-out and breakage of fibres. Fig. 11b shows that most of the fibres exhibited net tension failure supporting the hypothesis that fibre tension was the primary loading mechanism characterising the second linear regime of the stress-strain curve in Fig. 3a and Fig. 7b. Fracture surfaces of individual fibres are shown in

Fig. 11c. (1)-B (Fig. 11C) shows the tensile fracture surface of a fibre. (1)-A (Fig. 11c) indicates two distinct fibre failure modes; tensile fracture and shear-band fracture at the same position. If the shear-band fracture was generated by the shear loading, the two adjacent fibres should show the same fracture surfaces assuming the shear loading was distributed uniformly in this local area. (1)-A in Fig. 11c shows the fracture process of fibre under localized bending. The shear cusps and a large amount of fibre fragmentation at the root part of fibre bundle, shown in the Fig. 11c, can be attributed to the mixed-mode loading including shear, compression and bending. Evidence of bending failure can be seen in (1)-B as well. Therefore, the shear-band like fibre fracture surface was not caused by shear loading but bending. The fractographic analysis suggests that matrix yielding and fracture under shear loading, permitted the fibres, perpendicular to the loaded edges, to rotate and take up 
loading in tension. Consequently, the fibres in the V-notched shear test specimens failed by a combination of tension and local bending. The corresponding shear fracture toughness is mainly attributed to the complex failure modes involving fibre tensile failure, fibre pull-out, fibre/matrix interface debonding, delamination and following fibre bending fracture. The main energy-dissipating mechanism raising the toughness of fibre composites could be the extensive fibre breakage, interfacial debonding and fibre pull-out events evident in Fig. 11 and Fig. 12. With reference to the schematic in Fig. 12, extensive fibre bundles were pulled out of the surrounding resin with crack advancement, with fracture occurring away from the crack plane. Similar observations have been reported by Lafan et al. [47], where the measured intralaminar fibre toughness of the thicker layers was nearly twice the value of the thinner ones due to larger bundles of fibres being pulled out. Pimenta and Pinho [48] proposed an analytical method considering debonding and pull-out of bundles from quasi-fractal fracture surfaces, in which the predicted debonding and pull-out fracture toughness were as high as $240 \mathrm{~kJ} / \mathrm{m}^{2}$ and $255 \mathrm{~kJ} / \mathrm{m}^{2}$ respectively.

\subsubsection{Assessment of the measured fracture toughness}

The fracture toughness governs the damage evolution in the final facture process. To validate this value, a simplified model based on cohesive zone model was presented here. While the energy absorbed due to the nonlinear shear behaviour is proportional to the volume of the specimen, the energy absorbed by the fracture process is proportional to the area created. Only the elastic internal energy at onset of failure contributes to the fracture process. The fracture energy is the integral of the shaded area in Fig. 2a. The results are given in the Fig. 13c. Assuming the energy was fully dissipated in a certain fracture plane, the shear model was simplified by a model with cohesive surface behaviour in the central notch plane shown in Fig. 13a. Different fracture toughness ranges from $G_{1}=2.358 \mathrm{~kJ} / \mathrm{m}^{2}\left(G_{I I c}\right.$ mode II interlaminar fracture toughness), $G_{2}=34.58 \mathrm{~kJ} / \mathrm{m}^{2}\left(G_{m s}\right.$

mode II intralaminar matrix fracture toughness) to $G_{4}=576.62 \mathrm{~kJ} / \mathrm{m}^{2}\left(G_{\text {lam_s }}\right.$ shear fracture toughness of cross-ply laminates based on essential work of fracture) were used in the model and the corresponding forcedisplacement curves were integrated to yield the fracture energy in Fig. 13b. Fig. 13c compares the fracture 
energy values from the experiment and simulation, indicating that the fracture toughness measured from the essential work of fracture (EWF) was suitable as an input value to dissipate a correct amount of fracture energy under shear loading.

\section{Modelling the non-linear behaviour}

\subsection{Constitutive law}

The developed Intralaminar Damage Model (IDM) is based on the continuum damage mechanics, proposed by Chaboche [49] and Lemaitre [50], as a method to determine the behaviour of a material under damage-inducing loads. The effective stresses are defined as stresses transmitted across the intact part of the cross-section in a Representative Volume Element (RVE). The damage tensor is a function of three monotonically increasing damage variables, bound by 0 (no damage) and 1 (complete failure), each relating to a form of damage mode under a different loading state; (i) $d_{11}^{T}$ refers to tensile damage in the fibre direction, (ii) $d_{11}^{C}$ refers to compressive damage in the fibre direction and (iii) $d_{\text {mat }}$ refers to matrix cracking due to a combination of transverse tension/compression and shear loading, which is a unified matrix damage mechanism and replaces the previous model presented in [4]. The components of the effective stress tensor, $\tilde{\sigma}$, and true stress tensor, $\sigma$, can be linked by the damage tensor, $\mathbf{D}$, undamaged material elasticity tensor $\mathbf{C}$ and the strain tensor $\varepsilon, \sigma=\mathbf{D} \tilde{\sigma}=\mathbf{D C} \varepsilon$.

\subsection{Non-linear shear response}

\subsubsection{Constitutive law}

Considerable plastic shear strain and modulus degradation was observed with several consecutive loadingunloading cycles applied to test specimens. Prior to damage initiation, shear loading and unloading occurs along gradients defined by the initial shear modulus $G_{i j}^{i n i}$ and degraded shear modulus $G_{i j}^{*}$, shown in Fig. 14a, respectively. The shear strain $\gamma_{i j}^{t}$ is decomposed into the elastic part $\gamma_{i j, e l}^{t}$ and the inelastic/plastic part $\gamma_{i j, i n}^{t}$,

$$
\gamma_{i j}^{t}=\gamma_{i j, e l}^{t}+\gamma_{i j, i n}^{t} . \quad i \neq j=1,2,3
$$

The elastic strain is given by, 


$$
\gamma_{i j, e l}^{t}=\tau_{i j} / G_{i j}^{*, t}
$$

According to plastic-damage theories, the plastic strain $\gamma_{i j, i n}^{t}=\gamma_{i j}^{t}-\gamma_{i j, e l}^{t}$ represents all irreversible deformations including those caused by matrix microcracks.

The stress-strain constitutive laws, at time step $t$, are represented by an exponential model,

$$
\tau_{i j}^{t}=\tau_{i j}\left(\gamma_{i j}^{t}\right)=\left\{\begin{array}{c}
\tau_{i j}^{Y}\left[\exp \left(\alpha \gamma_{i j}^{t}\right)-\exp \left(\beta \gamma_{i j}^{t}\right)\right], \quad \gamma_{i j} \geq 0 \\
\tau_{i j}^{Y}\left[-\exp \left(-\alpha \gamma_{i j}^{t}\right)+\exp \left(-\beta \gamma_{i j}^{t}\right)\right], \quad \gamma_{i j}<0
\end{array} .\right.
$$

where $\tau_{i j}^{Y}$ is the initial yield strength, determined by the $2 \%$ offset strain point, $\alpha$ is a strain hardening coefficient and $\beta$ controls the initial shear modulus and elastic-plastic transition region. To characterize the degradation of the secant shear modulus, a degraded shear modulus, $G_{i j}^{*, t}$, was introduced and a strain-degraded modulus curve is shown in Fig. 16. The degradation modulus was coupled with the plastic deformation in the constitutive relation, making it convenient to obtain the fitting parameters from experiment results,

$$
G_{i j}^{*, t}=p_{1} \exp \left(p_{2}\left|\gamma_{i j}^{t}\right|\right)+p_{3} \exp \left(p_{4}\left|\gamma_{i j}^{t}\right|\right) \text {. }
$$

\subsubsection{Isotropic hardening model}

The capability of the proposed model to capture both non-linearity and different loading and unloading paths allows stress-strain hysteresis phenomena be accurately reproduced by the VUMAT subroutine, which is illustrated in Fig. 14b and Fig. 15b (flow chart), showing the steps involved in determining the final load state using elastic predictor method. The nominal stress is updated based on an explicit integration scheme.

In the case of unloading and reloading, an initial stress state $\left(\gamma_{i j}^{t}, \tau_{i j}^{t}\right)$ is reached after partial unloading along the in-situ shear modulus $\left(G_{i j}^{*}\right)$. The stress state after subsequent reloading to $\gamma_{i j}^{t+\Delta t}$ depends on whether plastic yielding has occurred. At a stress state below the yield stress, the material behaves elastically. Once yielding occurred, stress is updated according to the yield surface. For a material under a reversed loading condition, the subsequent yield stress is determined by the isotopic hardening approach, which assumes the reversed 
compressive/shear yield stress is equal to the tensile/original yield stress $(|A B|=|B C|)$. Isotropic hardening only applies while the loading remains below the threshold of matrix damage initiation $\left(d_{i j}^{I I, t}=0\right)$. Once matrix cracking initiates, unloading occurs along the reduced secant shear modulus to the permanent plastic strain $\gamma_{i j, i n}^{o}$ at damage initiation. Typical cyclic loading response with increasing amplitude and corresponding damage parameter are shown in Fig. 16a.

\subsection{Progressive failure}

\subsubsection{Damage initiation}

A strain based damage initiation function was used, for simplicity, to model the material response in the longitudinal direction. The failure initiation criterion based on Puck and Schürmann's [51] and Catalanotti et al. [52] was used for predicting matrix damage behaviour. The failure criteria for fibre-dominated mode and matrix dominated mode were given as follows,

Fibre-dominated

$$
\begin{aligned}
& \varepsilon_{11}>0, F_{11}^{T}\left(\varepsilon_{11}\right)=\left(\frac{\varepsilon_{11}}{\varepsilon_{11}^{O T}}\right)^{2} \geq 1 \\
& \varepsilon_{11}<0, F_{11}^{C}\left(\varepsilon_{11}\right)=\left(\frac{\varepsilon_{11}}{\varepsilon_{11}^{O C}}\right)^{2} \geq 1 \\
& \text { Matrix-dominated } \quad \sigma_{N N} \leq 0, F(\theta)=\left(\frac{\tau_{L N}}{s_{12}-\mu_{L N} \sigma_{N N}}\right)^{2}+\left(\frac{\tau_{N T}}{S_{23}-\mu_{N T} \sigma_{N N}}\right)^{2} \\
& \sigma_{N N}>0, F(\theta)=\left(\frac{\sigma_{N N}}{S_{23}}\right)^{2}+\left(\frac{\tau_{L N}}{S_{12}}\right)^{2}+\left(\frac{\tau_{N T}}{S_{23}}\right)^{2}+\lambda\left(\frac{\sigma_{N N}}{S_{23}}\right)\left(\frac{\tau_{L N}}{S_{12}}\right)^{2}+\kappa\left(\frac{\sigma_{N N}}{S_{23}}\right)
\end{aligned}
$$

The criterion will be determined whether the normal stress in the fracture plane $\sigma_{N N}$ is compressive or tensile. Parameters $\kappa$ and $\lambda$ are given by $\kappa=S_{23}^{2}-\left(Y^{T}\right)^{2} / S_{23} Y^{T}, \lambda=2 \mu_{L N} S_{23} / S_{12}-\kappa, S_{12}$ and $S_{23}$ are the shear strengths. The transverse friction coefficients, defined in [13], are based on Mohr-Coulomb theory where $\mu_{N T}=-1 / \tan \left(2 \theta_{f}\right), S_{23}=Y^{C} / 2 \tan \left(\theta_{f}\right)$ and $\mu_{L N}=\mu_{N T} S_{12} / S_{23}, Y_{C}$ is the transverse compressive strength, the initiation strain $\varepsilon_{11}^{O T(C)}=X^{T(C)} / E_{11}$. The fracture plane orientation, $\theta_{f}$, is typically found to be approximately $53^{\circ}$ for unidirectional composites [13] under uniaxial transverse compressive loading. 


\subsubsection{Damage evolution}

The overall progressive failure process can be represented by three stages shown in Fig. 16b. The first stage is initially characterized by plastic deformation and matrix micro-cracking. The increase in crack density leads to micro-crack coalescence and then to damage saturation. In the second stage, fibre rotation occurs, while the stiffness slightly decreases and the damage almost remains constant. At the final stage, a number of damage modes develop rapidly leading to a corresponding rapid reduction in stiffness and fracture. Two parameters are introduced to describe the matrix-dominated damage propagation, $d_{m a t}$, under shear loading: (i) shear damage in the strain hardening part, $d_{i j}^{I}$, and (ii) shear damage in the strain softening part, $d_{i j}^{I I}$.

$$
\begin{gathered}
d_{m a t}=d_{i j}^{I}+d_{i j}^{I I}, \\
d_{i j}^{I}=1-G_{i j}^{*} / G_{i j}^{i n i}, \\
d_{i j}^{I I}=d_{i j}^{I}+\left(1-d_{i j}^{I}\right) \frac{\gamma_{i j}^{f}-\gamma_{i j, i n}^{o}}{\gamma_{i j}^{f}-\gamma_{i j}^{o}}\left(\frac{\gamma_{i j}-\gamma_{i j}^{o}}{\gamma_{i j}-\gamma_{i j, i n}^{o}}\right),
\end{gathered}
$$

where $\gamma_{i j}$ is the current shear strain, $\gamma_{i j}^{f}$ is the final failure shear strain, $\gamma_{i j, i n}^{o}$ is the inelastic strain at the onset of fracture. In order to account for irreversibility, the damage variable as a function of analysis time, $t$, is defined as

$$
\left\{\begin{array}{c}
d_{\text {mat }}(t+\Delta t)=\max \left\{0, \min \left\{1, d_{\text {mat }}(t+\Delta t)\right\}\right\} \\
d_{\text {mat }}(t+\Delta t) \geq d_{i j}(t)
\end{array}, i=1,2,3 .\right.
$$

Damage is triggered when the shear strength, $\tau_{i j}^{o}$, is reached and the response follows a negative tangent stiffness resulting in the softening of the secant shear modulus, with increasing applied strain, to $\left(1-d_{m a t}\right) G_{i j}^{*}$, shown by path 3 in Fig. 14a. Consequently, final failure strain, $\gamma_{i j}^{f}$, is determined by,

$$
\gamma_{i j}^{f}=\frac{2 g_{i j}}{\tau_{i j}^{o}}+\gamma_{i j, i n}^{o}
$$

where $\gamma_{i j, i n}^{o}$ is the plastic strain at the onset of failure. Mesh objectivity of the model was achieved by employing the crack-band model of Bažant and Oh [53], where a characteristic length of the finite element (equivalent to a 
RVE), $\mathrm{g}_{i j}=\Gamma_{i j} / l^{*} . l^{*}$ and the corresponding fracture toughness $\Gamma_{i j}$ were used. $\mathrm{g}_{i j}$ is the volumetric energy release rate associated with elastic fracture energy. A quadratic interpolation function for the fracture energy in the mix-mode case was described in [3] to account for the multidirectional loading cases. An accurate measure of the characteristic length is the ratio of the elemental volume $V$ and fracture plane area $A, l^{*}=V / A$, described in [3].

\subsection{Modelling results}

\subsubsection{Finite element model}

Three dimensional finite element models were developed, including the V-notched specimen, with appropriate boundary conditions. The nodes in the left and right clamped areas were all constrained to reference points. A vertical constant velocity was applied on reference point at the left half and the reference point at the right half was fixed in all three coordinate directions. All finite element analyses were performed using the software package ABAQUS 6.12/EXPLICIT [54]. The numerical damage models were implemented in a user-defined material subroutine, VUMAT. Fig. 15 outlines the overall structure and non-linear shear part of the IDM as implemented in the VUMAT. The developed IDM assesses damage in a continuous fibre composite ply. Fibre-dominated damage is primarily associated with loading along the fibre direction. The anticipated damage will occur in the form of net fibre pull-out and breakage in tension and predominantly fibre kink band formation when loaded in compression. Matrix-dominated damage is primarily associated with transverse and shear loading, which leads to plasticity and formation of cracks in the matrix material. The use of a CDM based softening constitutive relationship necessitates the determination of a characteristic length to correctly scale the critical energy density. During the solution process, the analysis will pass strain values to the subroutine. It is the role of the subroutine to calculate a suitable stress. This is then fed back into the analysis which determines updated deformations. This process is repeated for each element at every time increment. 


\subsubsection{Laminates level model}

To verify the three-dimensional phenomenological model, the overall stress-strain response measured from the cross-ply laminates, Fig. 17c was utilized directly as the constitutive law to express the laminate non-linear behaviour. The overall fracture toughness obtained from the essential work of fracture was attributed to the cohesive fracture surface, where the surface-based cohesive behaviour in ABAQUS/Explicit [54] was used to capture delamination using a bilinear traction-separation relationship. The input data used is given in Table $2[42$, 55]. The specimen was modelled as a homogenised part where the global stiffness was calculated based on classical laminate theory.

The stress-strain curve obtained from a single element test (denoted by 'Num' in Fig. 17b) correlates well with experimental results (denoted by 'Exp' in Fig. 17b). The presented model was capable of reproducing the nonlinear behaviour in the yielding and strain hardening part. The degraded stiffness and permanent plastic strain were shown to be in good agreement with experimental observations. The damage parameter represented by the dashed line can be divided into two stages. In the first stage, damage initially increased rapidly, representing microcracking, before reaching a plateau. This is consistent with the observed trend in modulus degradation. When the stress reached the macroscale damage initiation criterion, the damage started to increase rapidly until full fracture. The damage evolution was governed by the fracture toughness. Fig. 17a shows the strain contour obtained from DIC and FEA. The simulation was able to capture the stress concentration in the central notch region as well as the fibre rotation features. The cohesive fracture at a displacement of $6 \mathrm{~mm}$, illustrated by Fig. $17 \mathrm{~b}$, is a simplified representation of the failure mode in shear. In Fig. 17d, the overall load-displacement curve shows the model can capture the initial yielding part before the displacement reached $6 \mathrm{~mm}$. Afterwards, cohesive fracture was initiated, leading to a peak load mismatch between the experiment and simulation results. In the damage propagation part, the force-displacement history, predicted by the model, shows a larger final displacement, but the dissipated fracture energy was close to the experimental test. The models developed at the 
length scale of the laminate are ideal for preliminary design and optimization because such models are able to provide very fast predictions. However, models developed at laminate-scale level have three main disadvantages: loss of accuracy, loss of generality, and increased number of material properties, i.e. parameters need to be remeasured for different layups and geometries.

\subsubsection{Ply Level model}

It has been shown that the strain hardening part was mainly caused by the fibre rotation and corresponding fibre tension. During the fibre rotation stage, the microscopic inspection in Fig. 4 showed that the matrix was still able to sustain the fibres without apparent extensive matrix cracking. The matrix behaviour after yielding can be approximated as perfectly plastic to allow the decomposition of the lamina nonlinear shear behaviour from the overall laminate shear response. In this ply level model, the strain hardening part of the stress-strain curve, accompanied by fibre rotation, was not accounted for; an approach assuming the perfectly-plastic relationship used in other models $[56,57]$. The ply-level constitutive law was shown in Fig. 18a. Similar to the laminate level model, this model can still reproduce the stiffness degradation and two-stage damage evolution. The mode II fracture toughness measured by shear loading on a unidirectional laminate was used for the fracture toughness. The $0^{\circ} 190^{\circ} \mathrm{v}$-notched specimens were modelled using 24 individual plies. The interfaces between the individual plies were modelled with a cohesive surface contact law based on Benzeggagh-Kenane (BK) [58]. The material properties used are given in Table 2. The numerically predicted strain contours, at different loading stages, are compared with experimental results (Fig. 19a) and show good qualitative and quantitative agreement. The predicted structural deformation and uniformly distributed fibre debonding on the surface of v-notched specimens was similar to those observed experimentally. It can be clearly seen in Fig. 19b that the fibre tensile damage was initiated in the strain hardening region. This again confirmed that the elastic deformation of the fibres controls the overall behaviour during this stage. The displacement compatibility between matrix and fibre led to the progressive rotation of the fibre with applied shear strain and increased the axial stress sustained by the fibres. The green 
contours in Fig. 19c represent the damage accumulated in the plastic deformation region during initial yielding. The red contours (Fig. 19c) primarily represent the matrix damage which is concentrated in the central notch region and is shown to increase rapidly during the fracture process beyond a strain of $\gamma>48 \%$. The overall load-displacement response of the numerical test correlates well with the experimental tests (Fig. 18b) in the elastic region as well as the fibre rotation region and global fracture regime. The permanent deformation and degraded stiffness were well represented in the model when unloading was applied. The predicted peak load was shown to be in good agreement with the test response, indicating the failure criteria was able to predict the onset fracture of cross-ply laminates accurately under shear loading. The damage propagation part in the final stages, representing the energy dissipation, correlated well with experimental tests results. Different load-displacement curves using different $\alpha(0,0.16$ and 1.6$)$ and $\beta(-28.32$ and -66.34$)$ in Fig. 18b indicate that the strain hardening behaviour was mainly controlled by $\alpha$, while $\beta$ makes a contribution to the stiffness in the initial elastic part and elastic-plastic transition part. The good correlation of the ply-level model $(\alpha=0.16, \beta=-66.34)$ shows that it is feasible to use the decomposed non-linear shear behaviour assuming the perfectly-plastic properties of the matrix from the accurately measured laminate properties to predict the overall shear response. The presented model requires accurate determination of the non-linear behaviour to achieve a predictive capability of material response.

\section{Conclusions}

In this work, an experimental programme was conducted to characterize the intralaminar non-linear behaviour and fracture toughness associated with shear loading of carbon fibre (AS4)/ thermoplastic Polyetherketoneketone (PEKK) composite. V-notched cross-ply specimens, recommend by ASTM standard D7078/D7078M-12, were employed to investigate the non-linear response under pure shear loading. Both monotonic and cyclic loading were applied to study the shear modulus degradation and progressive failure. Fracture toughness associated with shear loading was measured based on the concept of essential work of fracture which is only proportional to the 
ligament area as an intrinsic material property. Excellent geometric similarity in the load-displacement curves was observed for ligament-scaled specimens. The main conclusions of this work can be drawn as follows:

- In-plane (intralaminar) shear behaviour of AS4/PEKK showed initial elastic response, followed by a nonlinear regime with the initiation of matrix plastic deformation and a linearly increasing plastic region controlled by the elastic deformation of fibres until final failure.

- The shear modulus of AS4/PEKK decreased dramatically during the initial matrix plasticity phase and then maintained a relatively constant value as the fibres picked up loading in tension.

- Fractographic images support the hypothesis that fibres failed in tension and bending in the final fracture process.

- The laminate fracture toughness associated with shear loading was determined using the theory of specific work of fracture, $G_{l a m_{\_} s}=576.62 \mathrm{~kJ} / \mathrm{m}^{2}$, which is utilized by the laminate-level model.

- The matrix intralaminar fracture toughness associated with shear loading was determined from by the area method, $G_{m s}=34.58 \mathrm{~kJ} / \mathrm{m}^{2}$, which is more suitable for ply-level modelling.

- The failure modes contributing to the fracture toughness were fibre/matrix interfacial debonding, fibre pullout and fibre breakage.

Based on the determined material properties, a composite non-linear damage model that accounts for inelastic deformation, stiffness degradation and load reversal was combined with a smear crack model which has shown a high degree of capability in predicting non-linear shear behaviour and corresponding fracture process. The measured fracture toughness was also validated in terms of dissipated fracture energy using the area method with a cohesive fracture surface. The main failure modes contributing to the fracture toughness were fibre breakage, fibre/matrix interfacial debonding and fibre pull-out. Laminate and ply scale models were verified against experimental results of $\mathrm{V}$-notched shear tests. The force-displacement curves and damage parameter maps, obtained from the numerical analysis, demonstrate that the model can capture both the qualitative and quantitative 
aspects of shear behaviour of composite laminates. This provides an opportunity to reduce the cost of the test programmes required for the certification of aircraft composite structures. Future work will focus on extending this computational damage model to capture high energy crush events including a large amount non-linear shear failure, hence delivering accurate assessments of crashworthiness of composite structures.

\section{Acknowledgement}

The corresponding author would like to acknowledge the financial support of Bombardier and the Royal Academy of Engineering. The authors would also like to gratefully acknowledge the funding from the Queen's University Belfast/China Scholarship Council (QUB/CSC) PhD Scholarship and the support from the Research Computing

Team at QUB in accessing the HPC facilities.

\section{References}

[1] Feo L, Marra G, Mosallam AS. Stress analysis of multi-bolted joints for FRP pultruded composite structures. Compos Struct. 2012;94(12):3769-80.

[2] Xiao Y, Ishikawa T. Bearing strength and failure behavior of bolted composite joints (part I: Experimental investigation). Compos Sci Technol. 2005;65(7-8):1022-31.

[3] Tan W, Falzon BG, Chiu LNS, Price M. Predicting low velocity impact damage and Compression-After-Impact (CAI) behaviour of composite laminates. Composites Part A. 2015;71(0):212-26.

[4] Faggiani A, Falzon BG. Predicting low-velocity impact damage on a stiffened composite panel. Composites Part A. 2010;41(6):737-49.

[5] Tan W, Falzon BG, Price M. Predicting the crushing behaviour of composite material using high-fidelity finite element modelling. Int J Crashworthiness. 2014;20(1):60-77.

[6] ASTM. D7078/D7078M-12. Standard Test Method for Shear Properties of Composite Materials by V-Notched Rail Shear Method. West Conshohocken, PA. 2012

[7] ASTM. D5379/D5379M-12. Standard test method for shear properties of composite materials by the V-notched beam method. West Conshohocken, PA. 2012

[8] ASTM. D4255/D4255M-15a. Standard Test Method for In-Plane Shear Properties of Polymer Matrix Composite Materials by the Rail Shear Method. West Conshohocken, PA. 2015

[9] Pinho S, lannucci L, Robinson P. Physically-based failure models and criteria for laminated fibre-reinforced composites with emphasis on fibre kinking: Part I: Development. Composites Part A. 2006;37(1):63-73.

[10] Bažant Z, Oh BH. Crack band theory for fracture of concrete. Mat Constr. 1983;16(3):155-77.

[11] Camanho PP, Davila CG. Mixed-mode decohesion finite elements for the simulation of delamination in composite materials. NASA-Technical Paper. 2002;211737(1):33.

[12] Moës N, Belytschko T. Extended finite element method for cohesive crack growth. Eng Fract Mech. 2002;69(7):813-33.

[13] Ladevèze $P$, Lubineau G. On a damage mesomodel for laminates: micro-meso relationships, possibilities and limits. Compos Sci Technol. 2001;61(15):2149-58.

[14] Alfano M, Lubineau G, Paulino GH. Global sensitivity analysis in the identification of cohesive models using full-field kinematic data. Int J Solids Struct. 2015;55:66-78.

[15] Blaysat B, Hoefnagels JPM, Lubineau G, Alfano M, Geers MGD. Interface debonding characterization by image correlation integrated with Double Cantilever Beam kinematics. Int J Solids Struct. 2015;55:79-91.

[16] Lubineau G. A Pyramidal Modeling Scheme for Laminates - Identification of Transverse Cracking. International Journal of Damage Mechanics. 2009.

[17] Lubineau G, Ladevèze P. Construction of a micromechanics-based intralaminar mesomodel, and illustrations in ABAQUS/Standard. Comp Mater Sci. 2008;43(1):137-45. 
[18] O'BRIEN TK, Martin RH. Round robin testing for mode I interlaminar fracture toughness of composite materials. J Compos Tech Res. 1993;15(4):269-81.

[19] Pinho ST, Robinson P, lannucci L. Fracture toughness of the tensile and compressive fibre failure modes in laminated composites. Compos Sci Technol. 2006;66(13):2069-79.

[20] Donadon MV, Falzon BG, lannucci L, Hodgkinson JM. Intralaminar toughness characterisation of unbalanced hybrid plain weave laminates. Composites Part A. 2007;38(6):1597-611.

[21] Catalanotti G, Camanho PP, Xavier J, Dávila CG, Marques AT. Measurement of resistance curves in the longitudinal failure of composites using digital image correlation. Compos Sci Technol. 2010;70(13):1986-93.

[22] Catalanotti G, Xavier J, Camanho PP. Measurement of the compressive crack resistance curve of composites using the size effect law. Composites Part A. 2014;56(0):300-7.

[23] Catalanotti G, Xavier J. Measurement of the mode II intralaminar fracture toughness and R-curve of polymer composites using a modified losipescu specimen and the size effect law. Eng Fract Mech. 2015;138:202-14.

[24] Bazant ZP, Planas J. Fracture and size effect in concrete and other quasibrittle materials: CRC press; 1997.

[25] Kwon HJ, Jar PYB. Toughness of high-density polyethylene in shear fracture. Int J Fracture. 2007;145(2):123-33.

[26] Kwon HJ, Jar PYB. Fracture toughness of polymers in shear mode. Polymer. 2005;46(26):12480-92.

[27] Rink M, Andena L, Marano C. The essential work of fracture in relation to J-integral. Eng Fract Mech. 2014;127:46-55.

[28] Sui GX, Wong SC, Yue CY. The effect of fiber inclusions in toughened plastics-part I: fracture characterization by essential fracture work. Compos Sci Technol. 2001;61(16):2481-90.

[29] van der Meer FP, Oliver C, Sluys LJ. Computational analysis of progressive failure in a notched laminate including shear nonlinearity and fiber failure. Compos Sci Technol. 2010;70(4):692-700.

[30] Fanteria D, Longo G, Panettieri E. A non-linear shear damage model to reproduce permanent indentation caused by impacts in composite laminates. Compos Struct. 2014;111:111-21.

[31] Sun C, Chen J. A simple flow rule for characterizing nonlinear behavior of fiber composites. J Compos Mater. 1989;23(10):1009-20.

[32] Voyiadjis GZ, Thiagarajan G. An anisotropic yield surface model for directionally reinforced metal-matrix composites. Int J Plasticity. 1995;11(8):867-94.

[33] Ladevèze $P$, Lubineau G. On a damage mesomodel for laminates: micromechanics basis and improvement. Mech Mater. 2003;35(8):763-75.

[34] van der Meer FP, Sluys LJ. Continuum Models for the Analysis of Progressive Failure in Composite Laminates. J Compos Mater. 2009.

[35] Totry E, Molina-Aldareguía JM, González C, Llorca J. Effect of fiber, matrix and interface properties on the in-plane shear deformation of carbon-fiber reinforced composites. Compos Sci Technol. 2010;70(6):970-80.

[36] Van Paepegem W, De Baere I, Degrieck J. Modelling the nonlinear shear stress-strain response of glass fibrereinforced composites. Part II: Model development and finite element simulations. Compos Sci Technol. 2006;66(10):146578.

[37] Van Paepegem W, De Baere I, Degrieck J. Modelling the nonlinear shear stress-strain response of glass fibrereinforced composites. Part I: Experimental results. Compos Sci Technol. 2006;66(10):1455-64.

[38] Vogler M, Rolfes R, Camanho P. Modeling the inelastic deformation and fracture of polymer composites-Part I: plasticity model. Mech Mater. 2013;59:50-64.

[39] Camanho P, Bessa M, Catalanotti G, Vogler M, Rolfes R. Modeling the inelastic deformation and fracture of polymer composites-Part II: smeared crack model. Mech Mater. 2013;59:36-49.

[40] Vyas GM, Pinho ST, Robinson P. Constitutive modelling of fibre-reinforced composites with unidirectional plies using a plasticity-based approach. Compos Sci Technol. 2011;71(8):1068-74.

[41] Falzon BG, Apruzzese P. Numerical analysis of intralaminar failure mechanisms in composite structures. Part I: FE implementation. Compos Struct. 2011;93(2):1039-46.

[42] Cytec. APC-2 PEKK Thermoplastic Polymer Technical Data Sheet. Cytec Engineering Materials. 2012.

[43] Arkhireyeva A, Hashemi S. Effect of temperature on work of fracture parameters in poly(ether-ether ketone) (PEEK) film. Eng Fract Mech. 2004;71(4-6):789-804.

[44] Cotterell B, Reddel JK. The essential work of plane stress ductile fracture. Int J Fracture. 1977;13(3):267-77.

[45] Chiu LNS, Falzon BG, Boman R, Chen B, Yan W. Finite element modelling of composite structures under crushing load. Compos Struct. 2015;131:215-28.

[46] ASTM. D1894-14. Standard Test Method for Static and Kinetic Coefficients of Friction of Plastic Film and Sheeting. West Conshohocken, PA,. 2014

[47] Laffan MJ, Pinho ST, Robinson P, lannucci L. Measurement of the in situ ply fracture toughness associated with mode I fibre tensile failure in FRP. Part II: Size and lay-up effects. Compos Sci Technol. 2010;70(4):614-21.

[48] Pimenta S, Pinho ST. An analytical model for the translaminar fracture toughness of fibre composites with stochastic quasi-fractal fracture surfaces. J Mech Phys Solids. 2014;66:78-102.

[49] Chaboche JL. Continuum Damage Mechanics: Part II-Damage Growth, Crack Initiation, and Crack Growth. Journal of Applied Mechanics. 1988;55(1):65-72.

[50] Lemaitre J, Chaboche J-L. Mechanics of solid materials: Cambridge university press; 1994. 
[51] Puck A, Schürmann H. Failure analysis of FRP laminates by means of physically based phenomenological models. Compos Sci Technol. 1998;58(7):1045-67.

[52] Catalanotti G, Camanho PP, Marques AT. Three-dimensional failure criteria for fiber-reinforced laminates. Compos Struct. 2013;95(0):63-79.

[53] Fleming DC. Modelling composite crushing initiation using a cohesive element formulation. Int J Crash. 2011;16(5):47585.

[54] Simulia. Abaqus 6.12 documentation. Providence, Rhode Island, US. 2012.

[55] Tan W, Falzon BG. Modelling the nonlinear behaviour and fracture process of AS4/PEKK thermoplastic composite under shear loading. 2015;Submitted.

[56] Preetamkumar M, Gilles L, Pierre L, Ana-cristina G. Validation of Intralaminar Behaviour of the Laminated Composites by Damage Mesomodel. 50th AIAA/ASME/ASCE/AHS/ASC Structures, Structural Dynamics, and Materials Conference: American Institute of Aeronautics and Astronautics; 2009.

[57] Vyas GM, Pinho ST. Computational implementation of a novel constitutive model for multidirectional composites. Comp Mater Sci. 2012;51(1):217-24.

[58] Benzeggagh M, Kenane M. Measurement of mixed-mode delamination fracture toughness of unidirectional glass/epoxy composites with mixed-mode bending apparatus. Compos Sci Technol. 1996;56(4):439-49. 


\section{Figures}

(a)
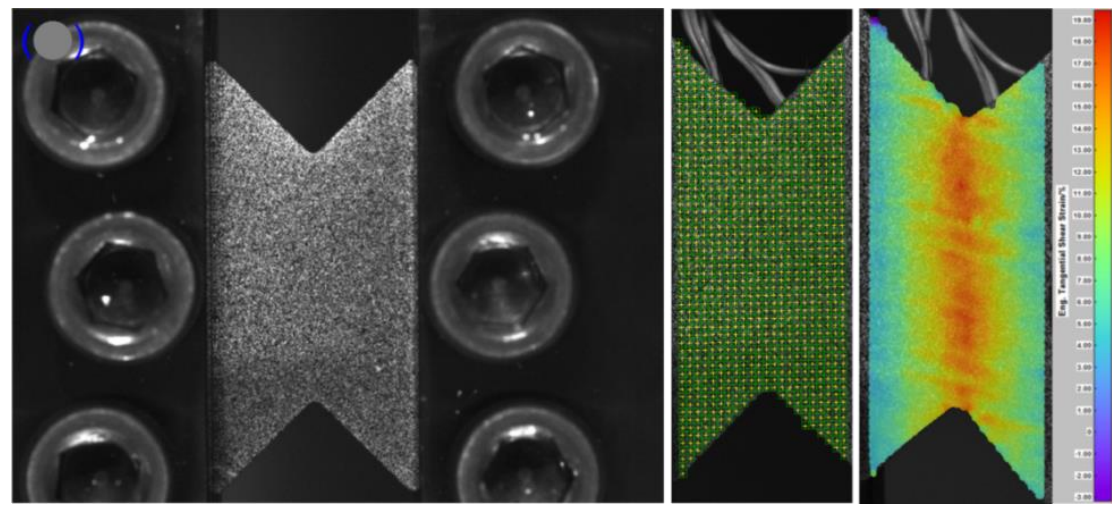

(b)

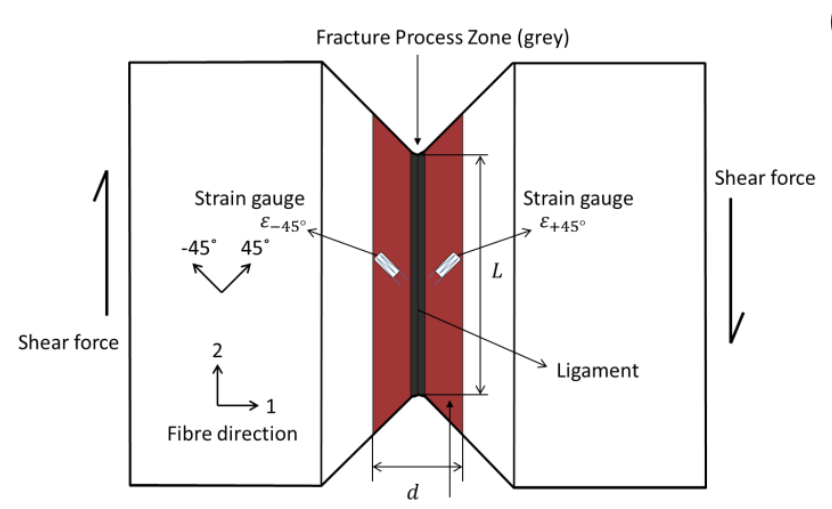

Plastic deformation zone (red) (c)

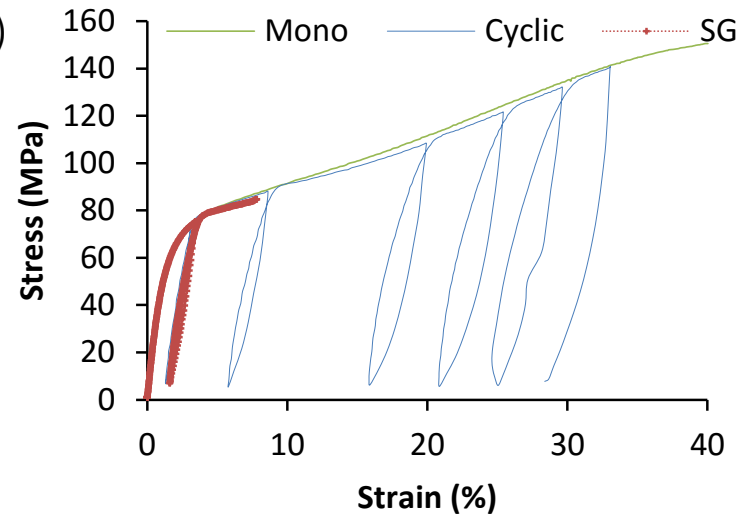

Fig. 1. (a) Shear strain field obtained from DIC (b) Inner fracture process zone and outer plastic deformation zone (c) comparison of stress-strain curves obtained with DIC and Strain gauges (SG).

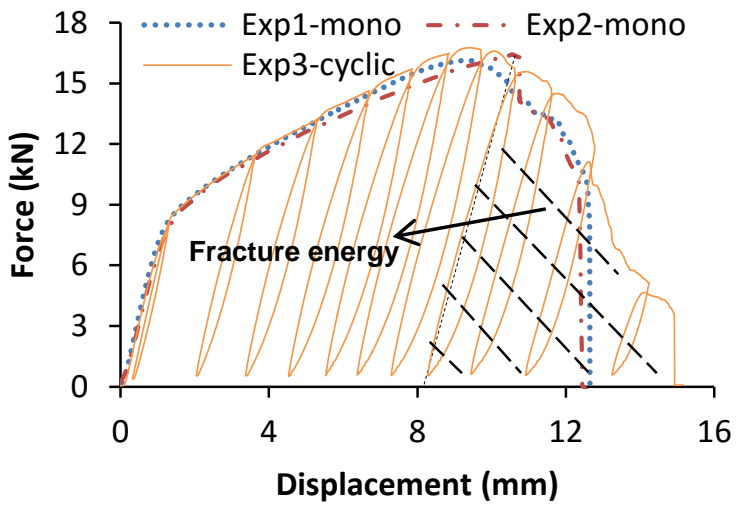

(a)

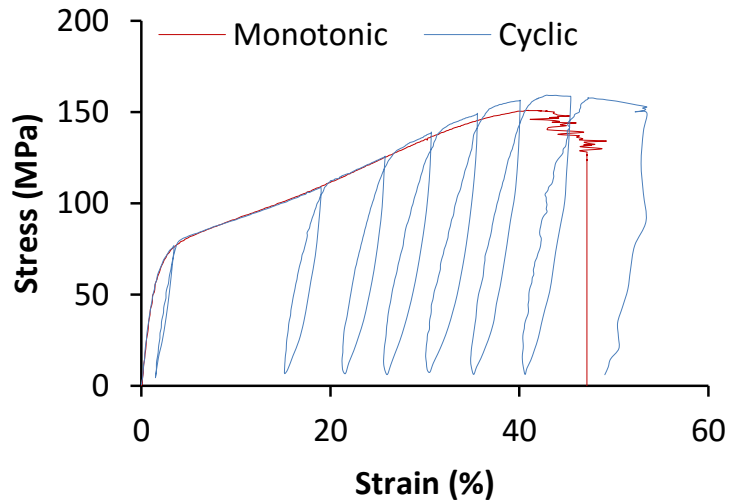

(b)

Fig. 2. (a) Load-displacement curves and (b) stress-strain curves of V-0/90 specimens 
(a)

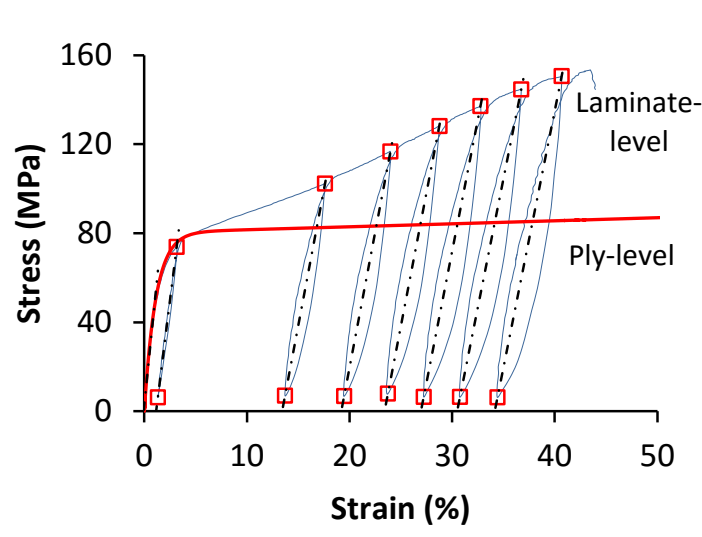

(b)

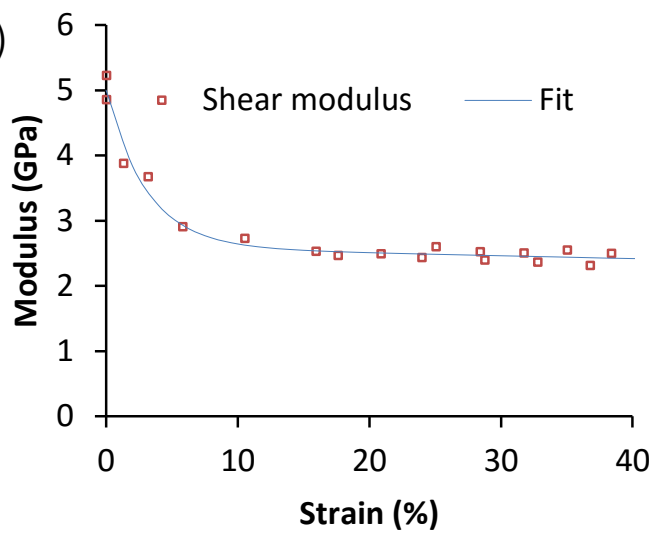

Fig. 3. (a) Stress-strain curves with several consecutive loading-unloading cycles and (b) stiffness degradation of

(a)

\section{V-0/90 specimens}

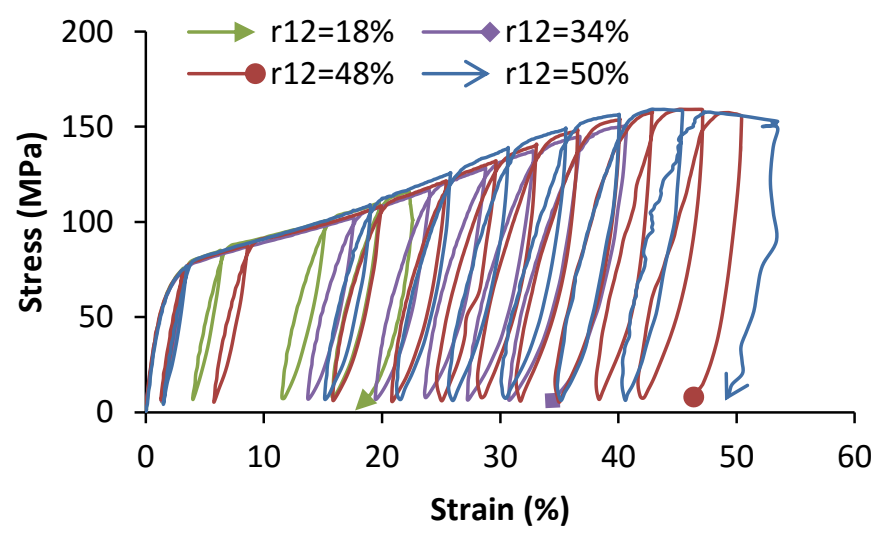

(b)

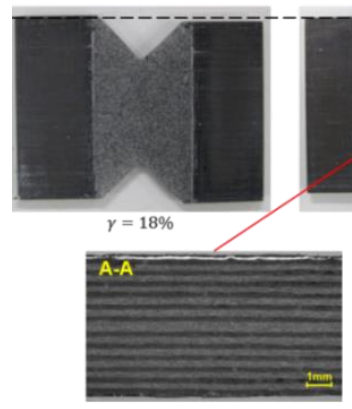

No apparent damage
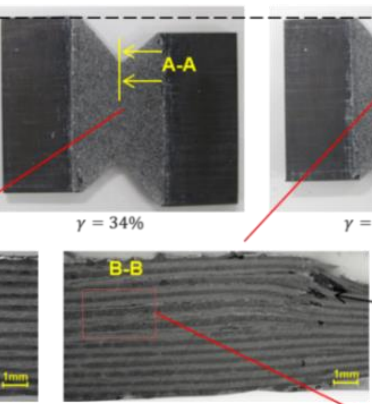

Apparent damage
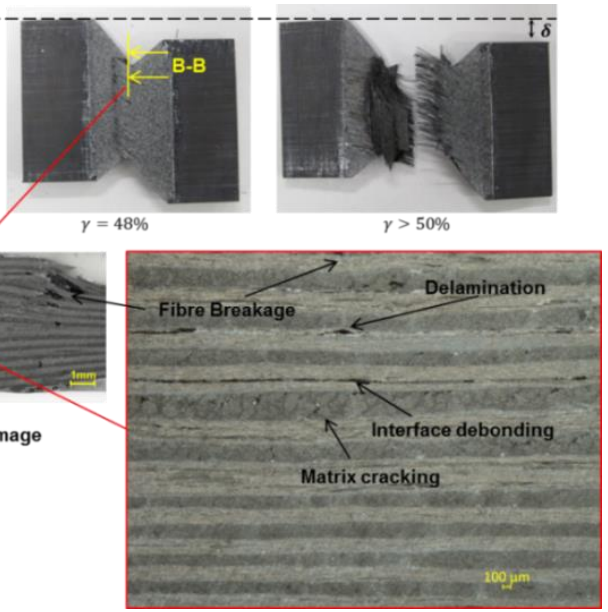

Fig. 4. (a) Stress-strain curves and (b)microscopies section of tested samples interrupted at different strain of V$0 / 90$ specimens 


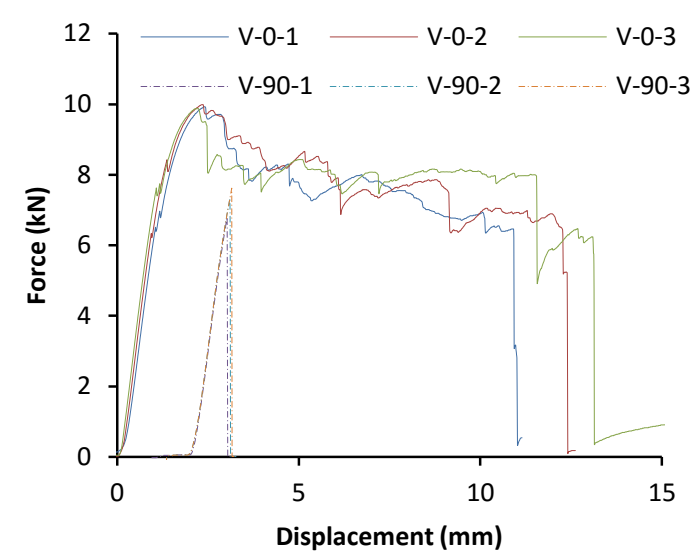

(a)

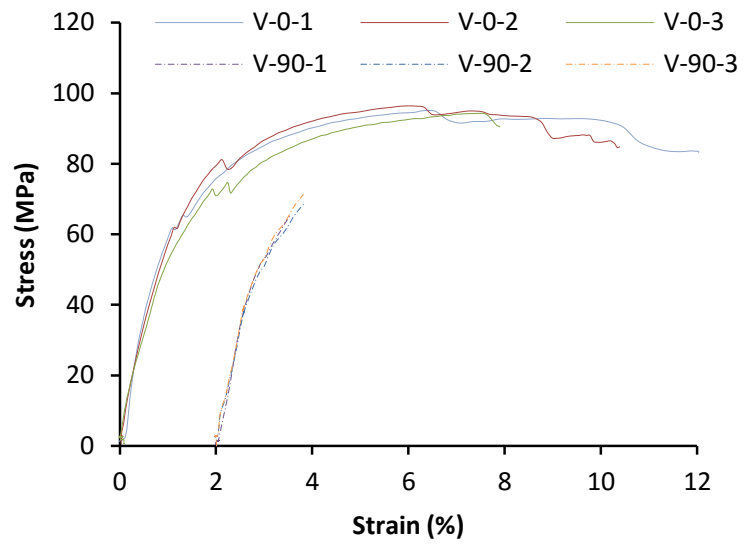

(d)

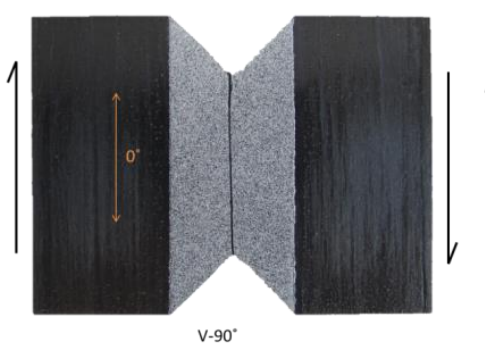

(c)

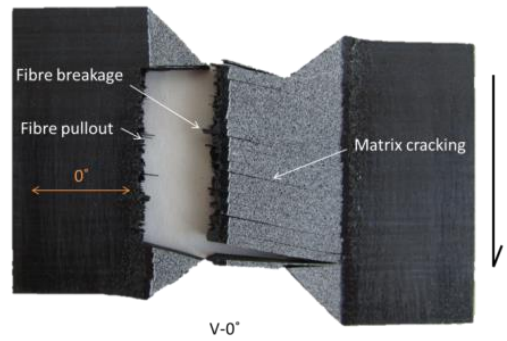

$\mathrm{V}-0^{\circ}$ (b)

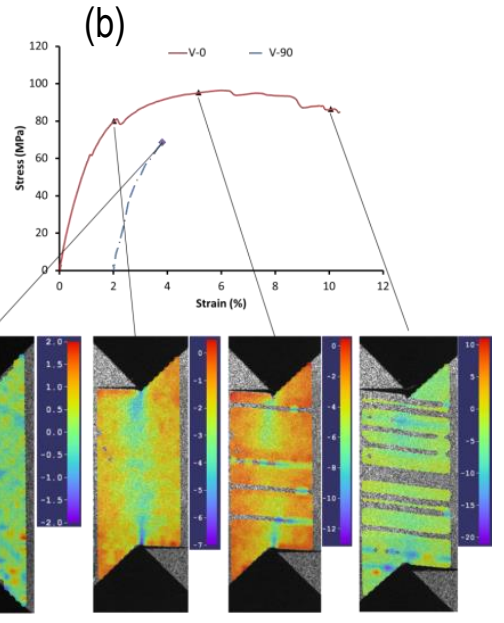

Fig. 5. V-0 and V-90 specimens: (a) Load-displacement curves (2mm shift for clarity), (b) stress-strain curves

Fig. 5. V-0 and V-90 specimens: (a) Load-displacement curves (2mm shift for clarity), (b) stress-strain curves ( $2 \%$ shift for clarity) for unidirectional laminate composites under shear loading parallel and perpendicular to the fibre orientation and (c) Tested specimens. (d) Failure process of the unidirectional laminate

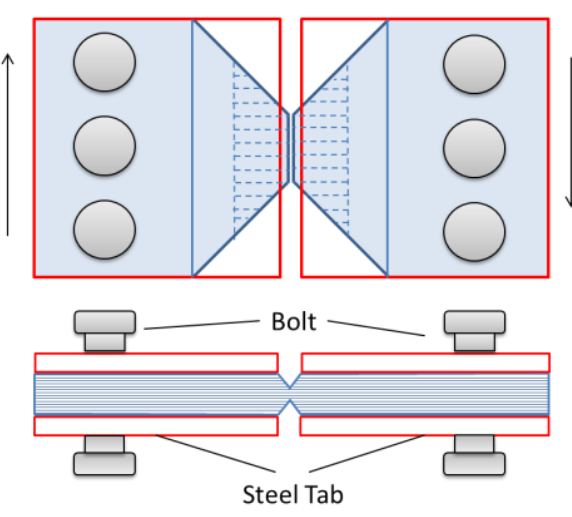

(a)
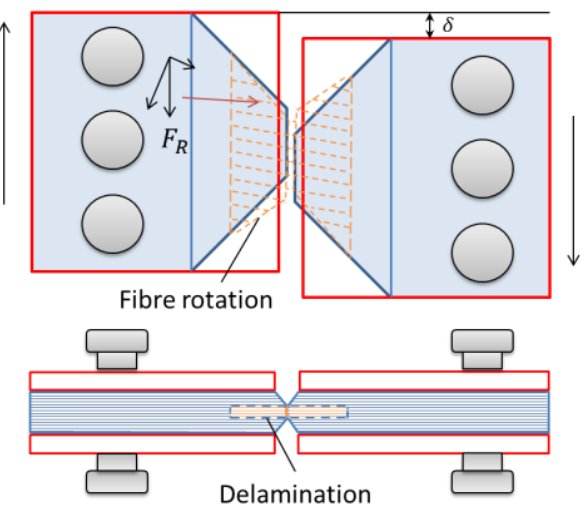

(b)

Fig. 6. (a) Fracture toughness associated with shear loading set-up and (b) fracture process 
(a)
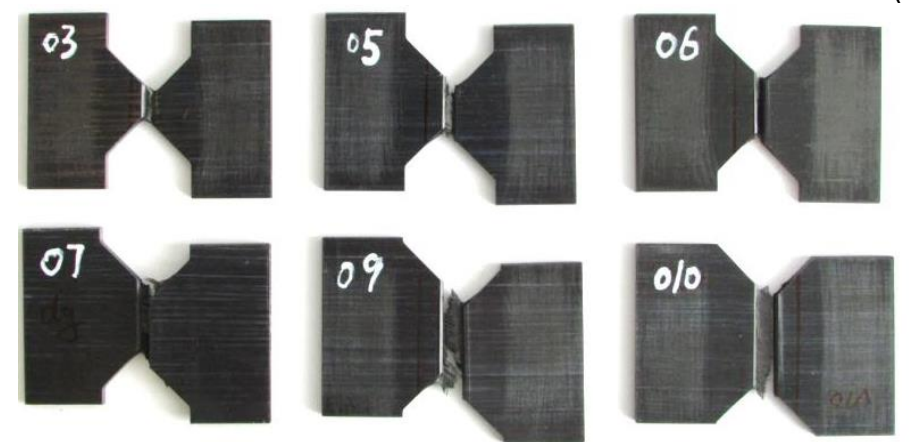

(b)

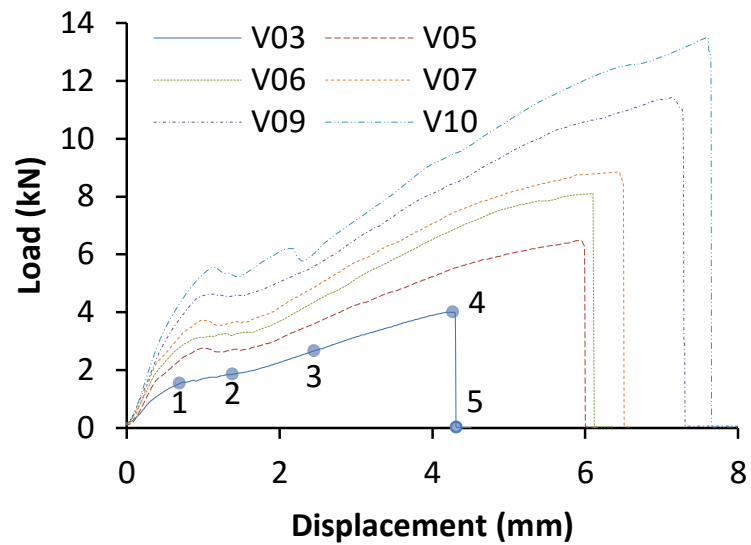

(c)

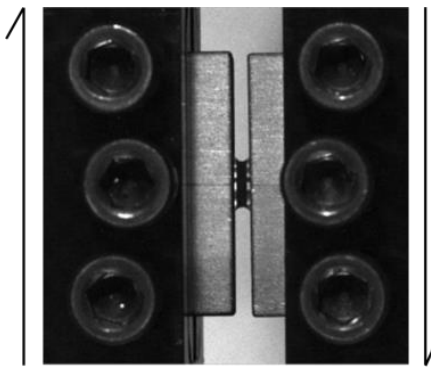

Setup

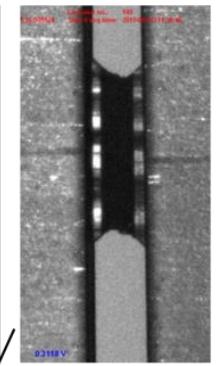

1

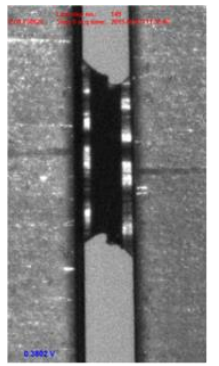

2

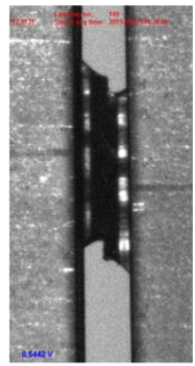

3

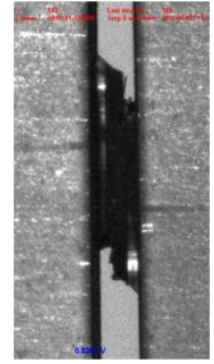

4

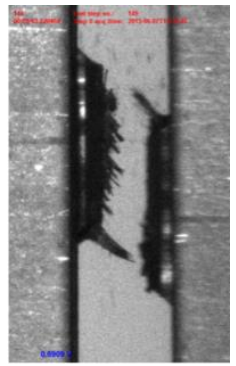

5

Fig. 7. (a)Tested specimens of different ligament length (b)load-displacement response and (c) shear fracture process at different stages of specimen $\mathrm{V}-0 / 90-03$
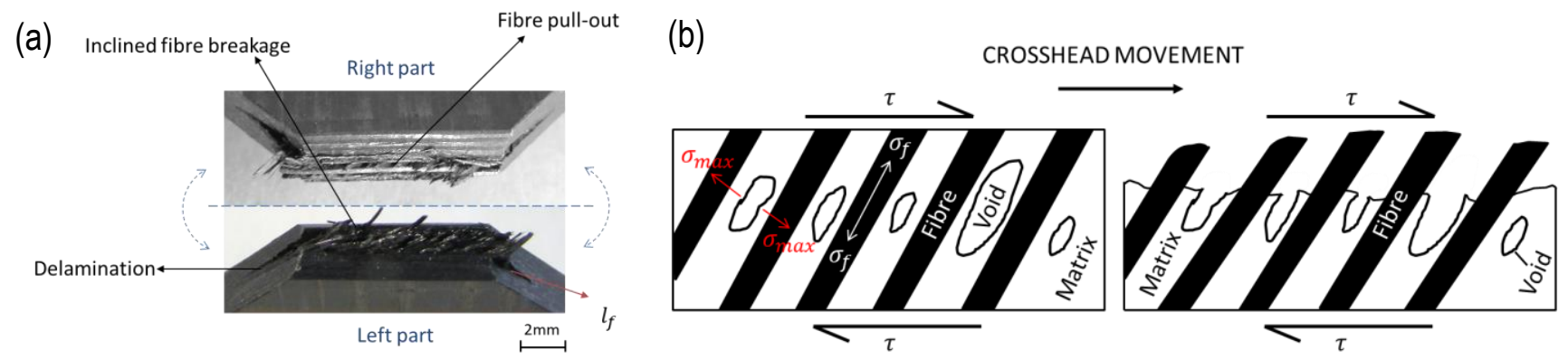

Fig. 8. (a) Final fracture surface and fibre pull-out of $\mathrm{V}-0 / 90-03$ and (b) schematic view of shear fracture process 

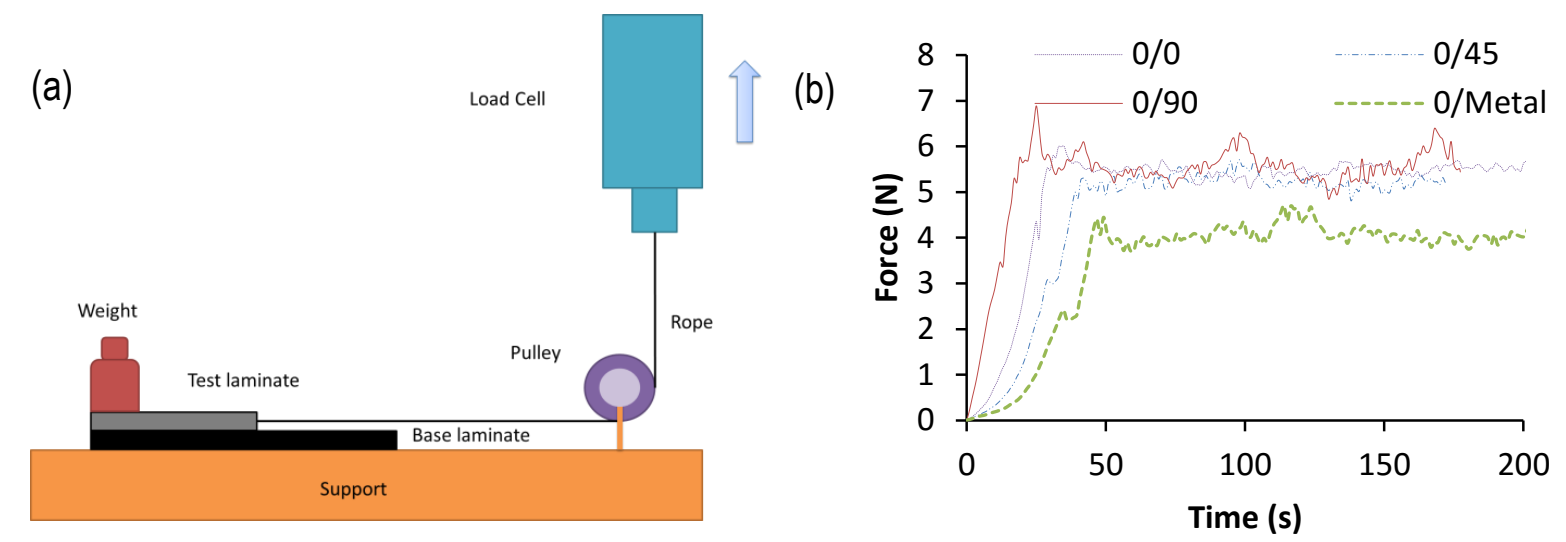

Fig. 9. (a)Friction test setup and (b)force-time history

(a)

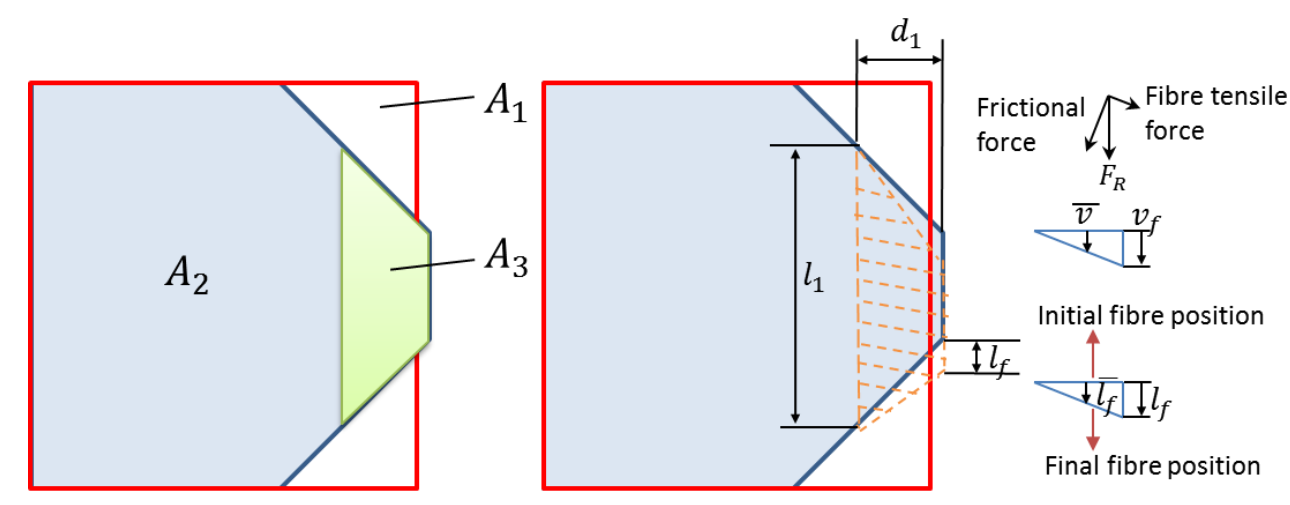

(b)

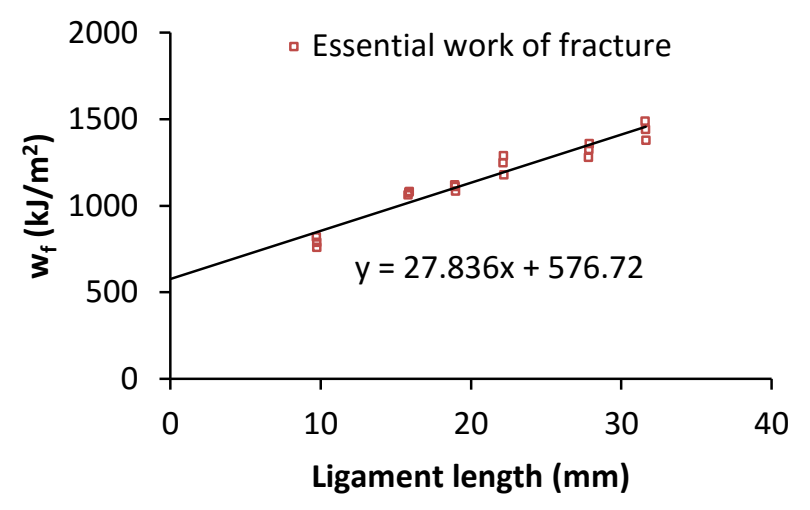

Fig. 10. (a) Calculation of the friction normal force and displacement and (b) typical specific work of fracture $w_{f}$ versus $L$ plots 


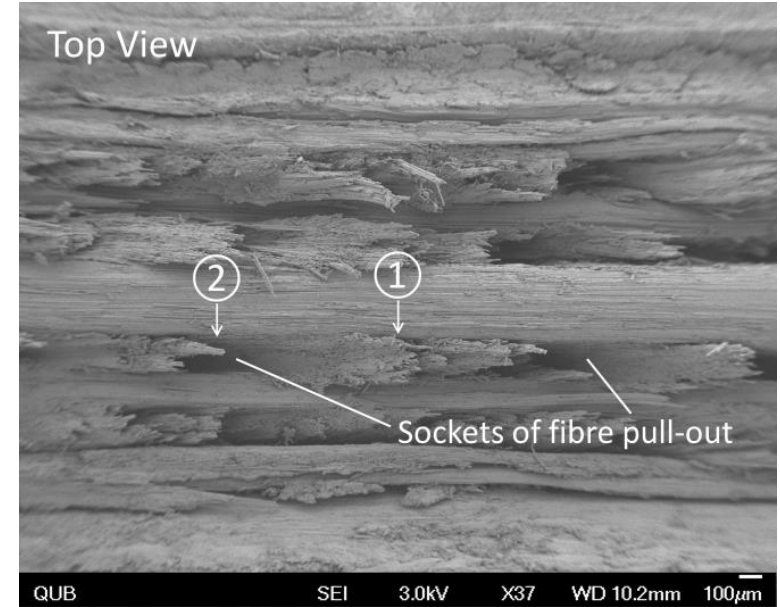

(a)

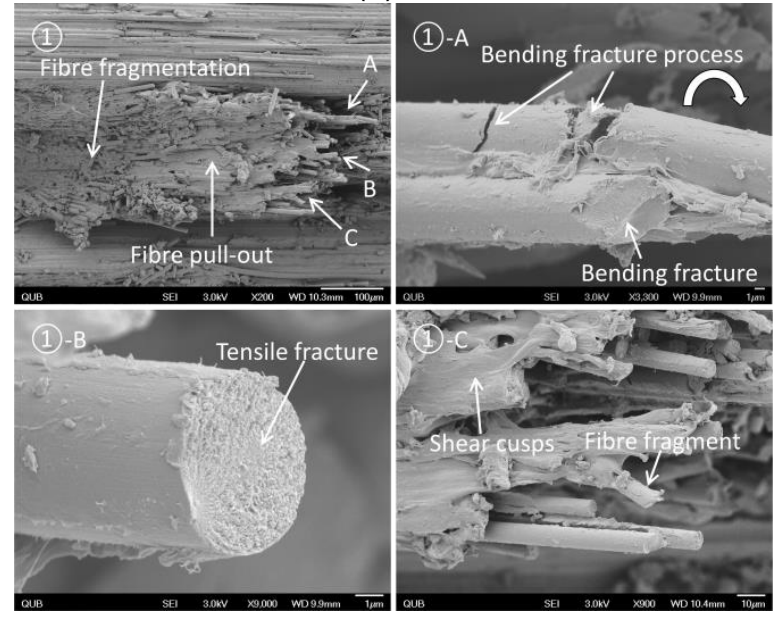

(c)

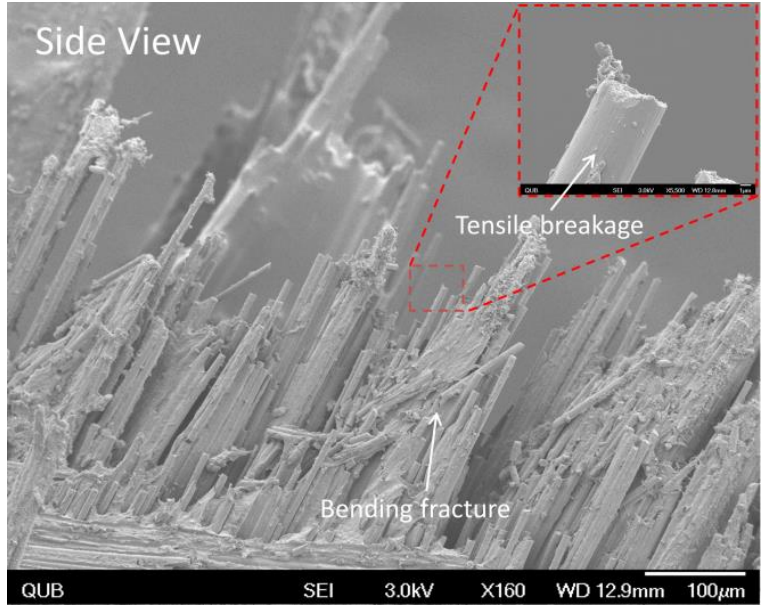

(b)

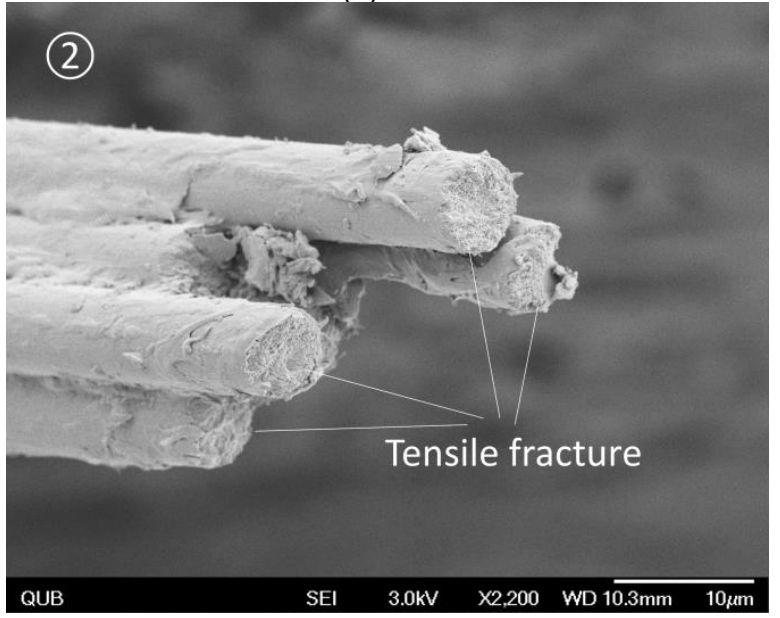

(d)

Fig. 11. Fractographic analysis of tested specimen V-0/90-03 (a) fracture surface - top view; (b)fracture surface side view;(c) high magnification images at location (1); (d) tensile fracture images at location (2)

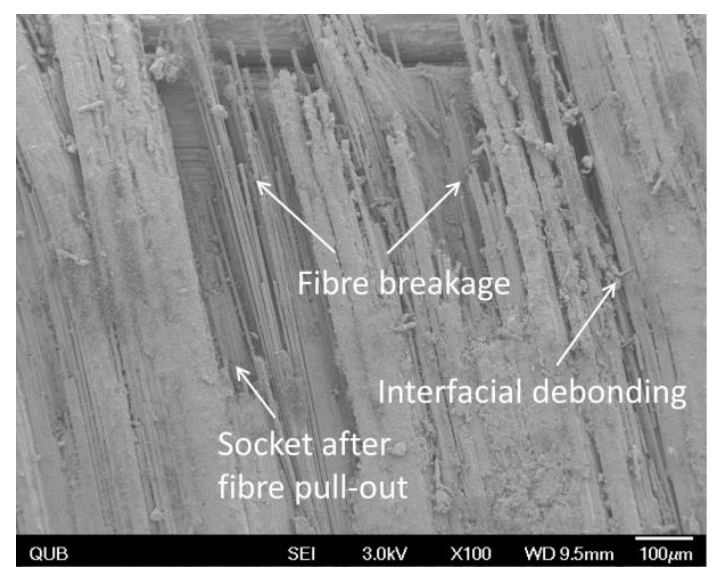

(a)

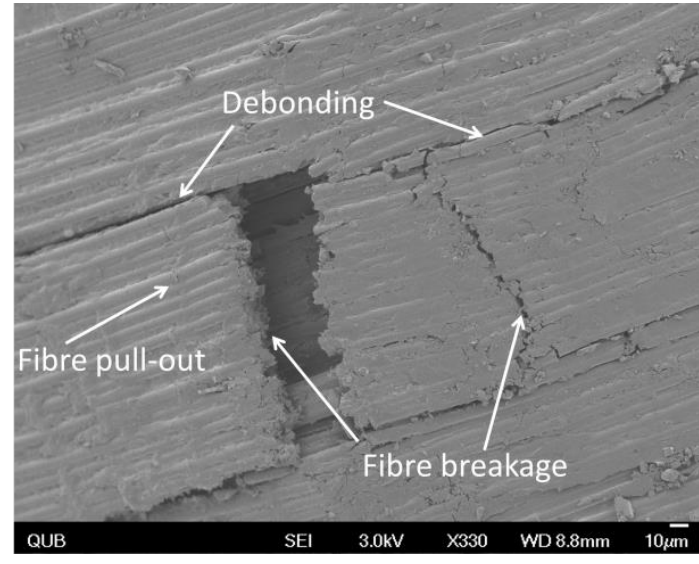

(b)

Fig. 12. SEM images of (a) fibre pull-out and (b) interface debonding of $V-0 / 90-03$ 

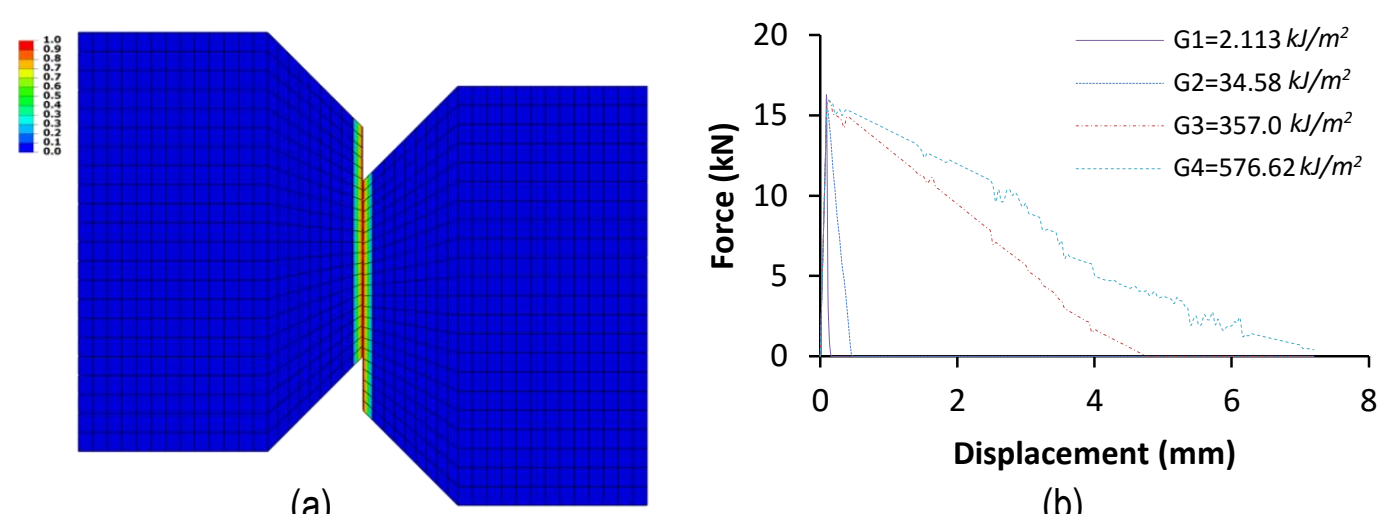

(a)

(b)

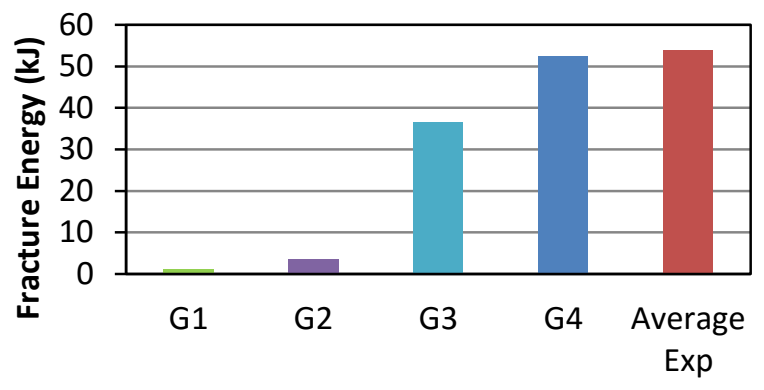

Different cases

(c)

Fig. 13. (a) cohesive fracture surface (b) force-displacement curves and (c) comparison of calculated fracture energy from experiment and simulation (G1 to G4) of V-0/90 specimens

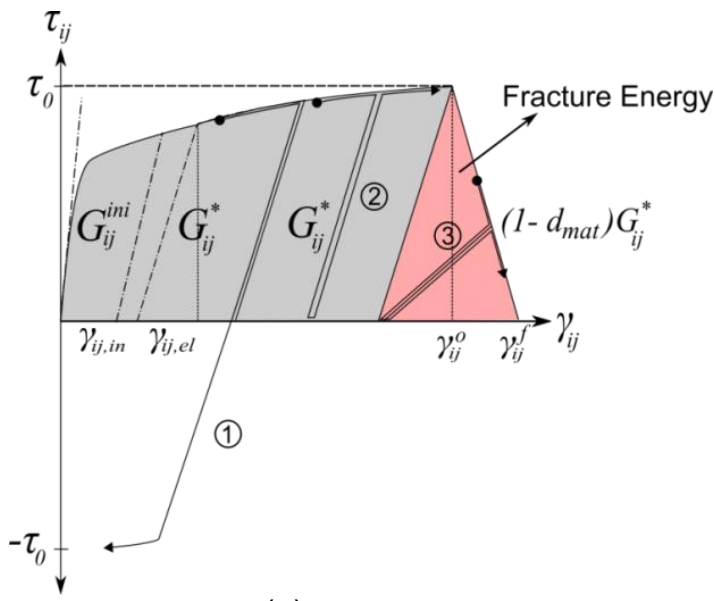

(a)

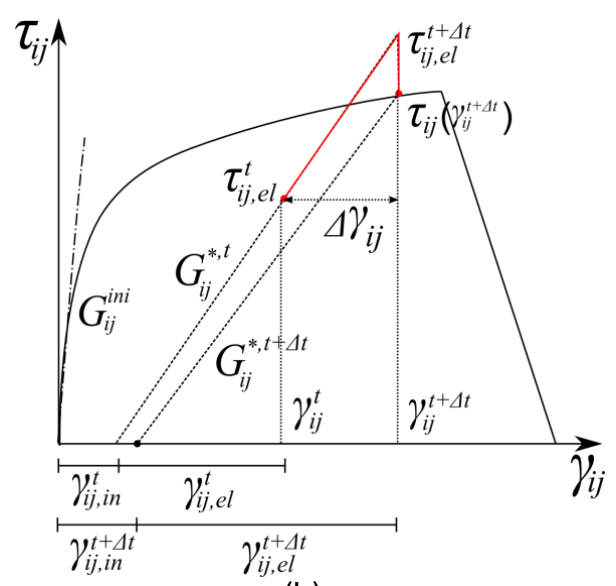

(b)

Fig. 14. (a) Proposed non-linear shear model and (b) elastic predictor method to determine stress state 

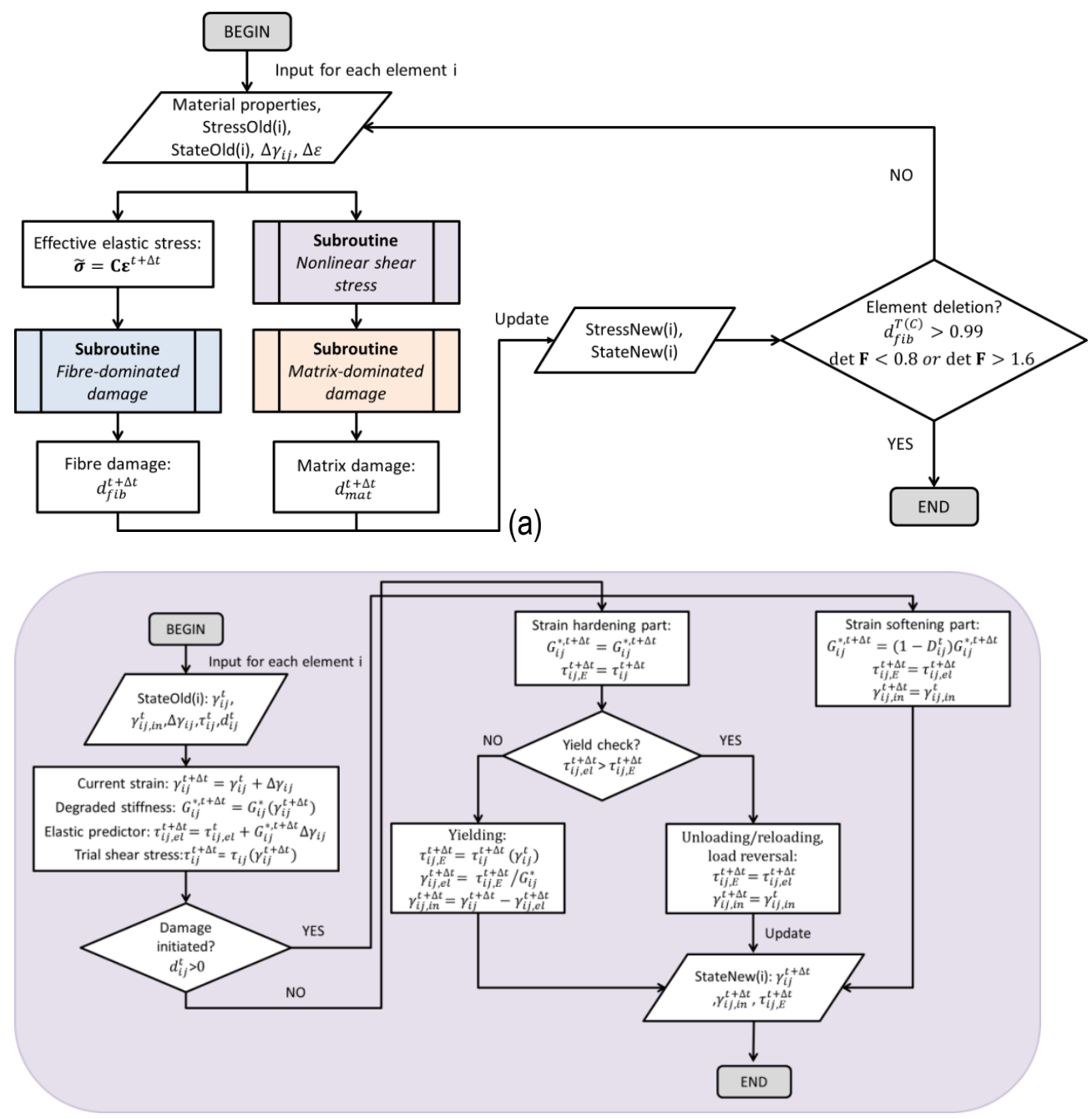

(b)

Fig. 15. (a) Overall subroutine flow chart and (b) highlighted non-linear shear subroutine

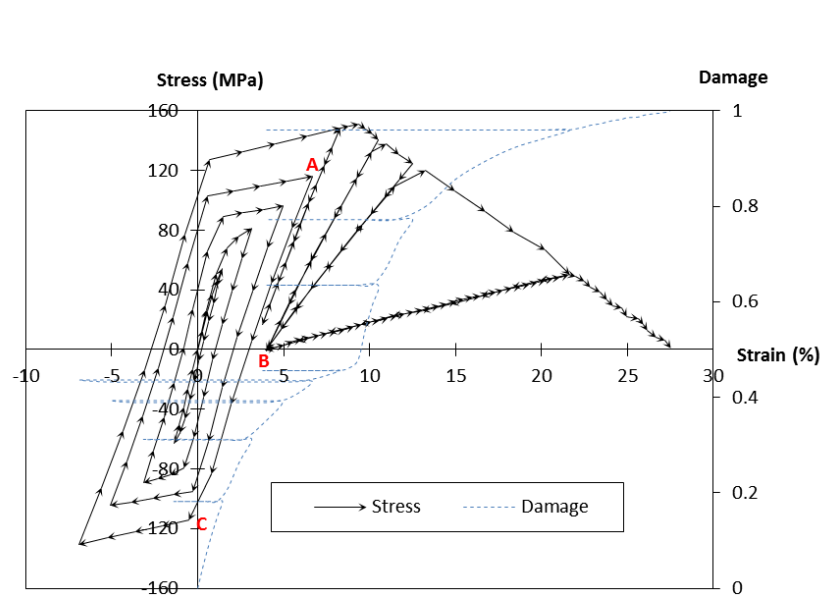

(a)
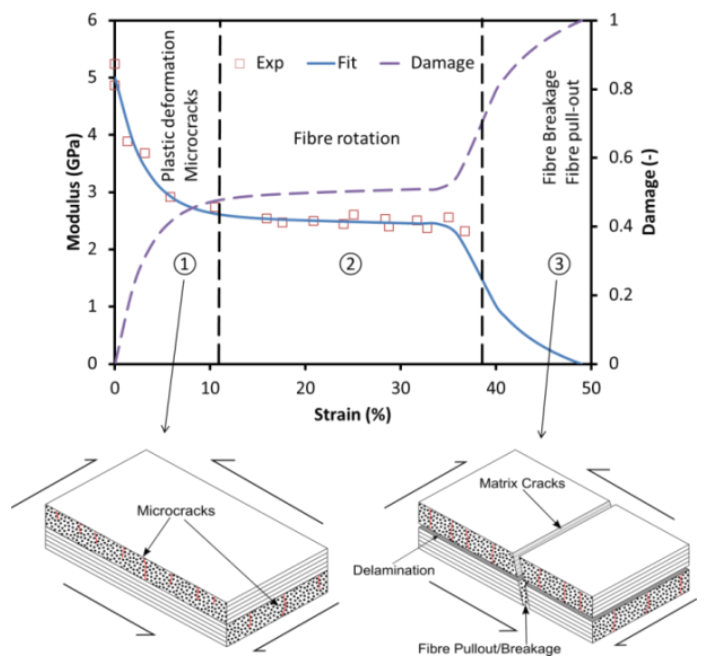

(b)

Fig. 16. (a) Cyclic loading and (b) degraded shear modulus and damage propagation curves 


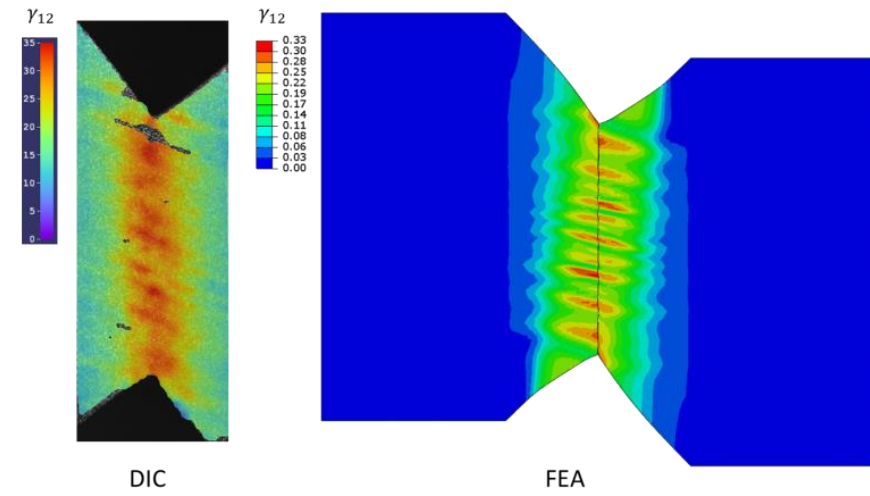

(a)

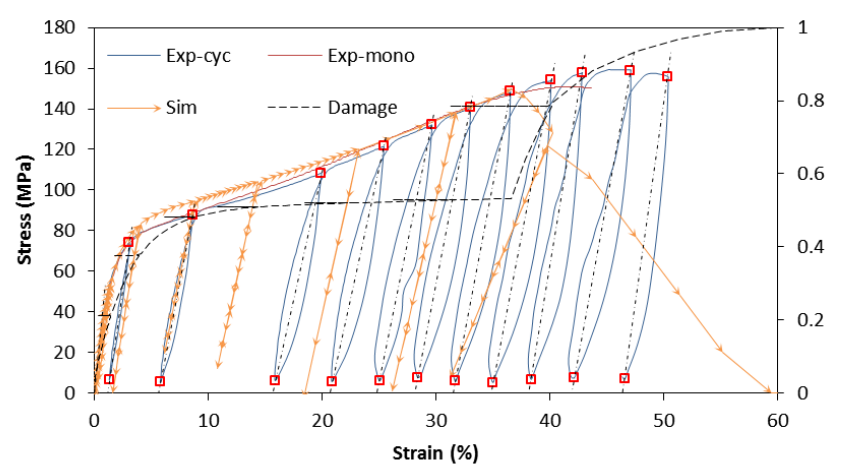

(c)

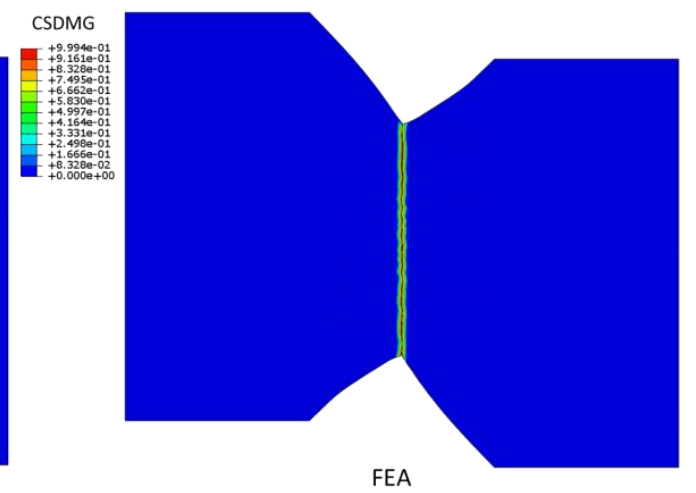

(b)

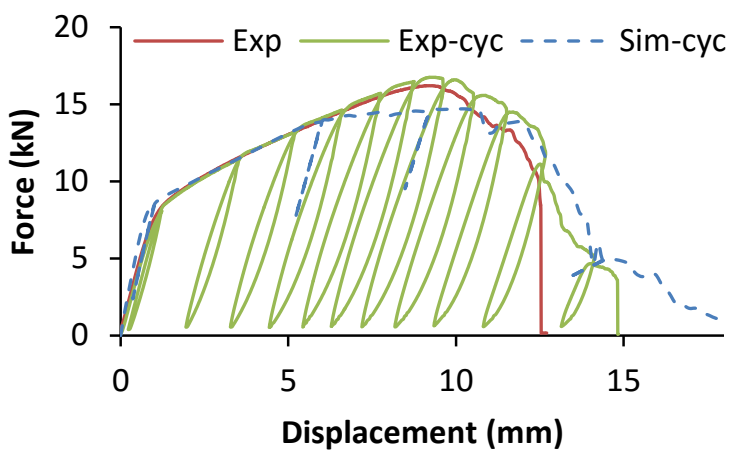

(d)

Fig. 17. Predicted (a) strain contour of DIC, (b) central cohesive fracture surface, (c) Stress-strain curves for laminate-level model and (d) load-displacement curves of V-0/90 specimens

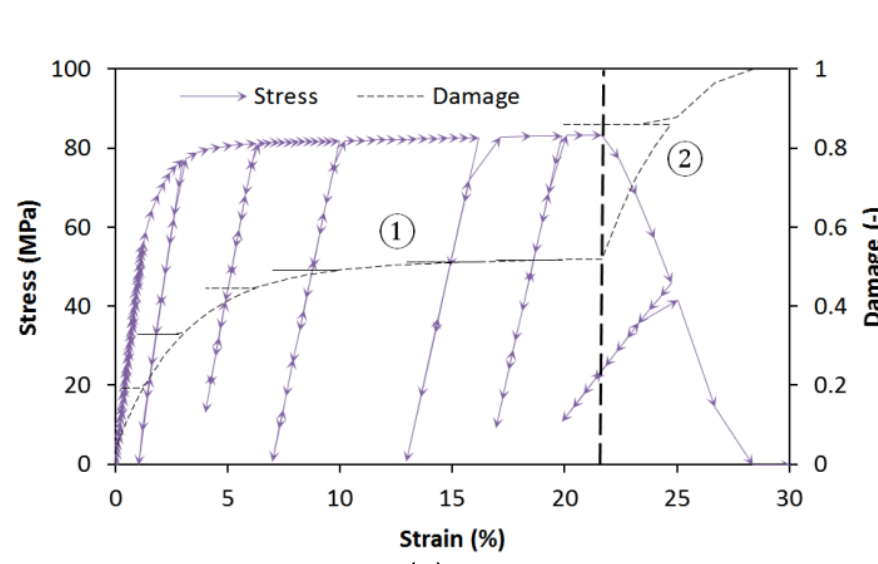

(a)

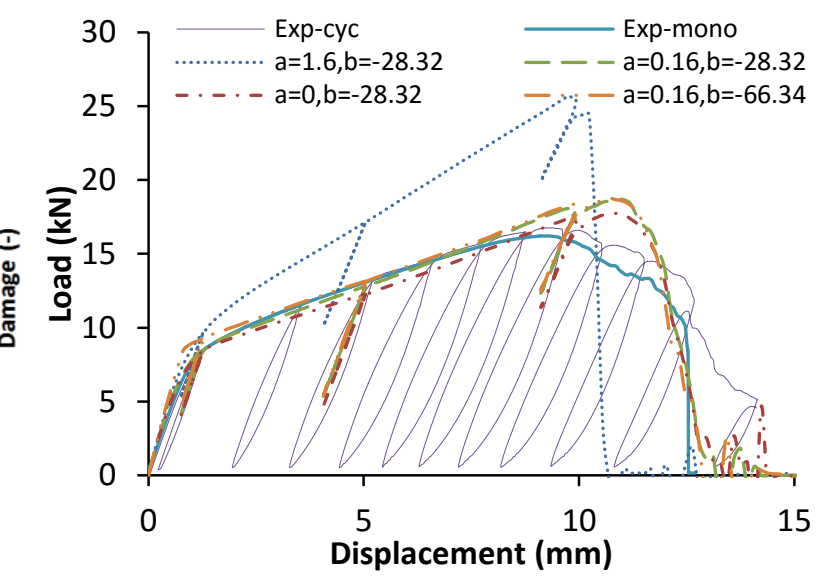

(b)

Fig. 18. (a) Stress-strain curves for ply-level model and (b) predicted load-displacement curves of $\mathrm{V}$-0/90 specimens 


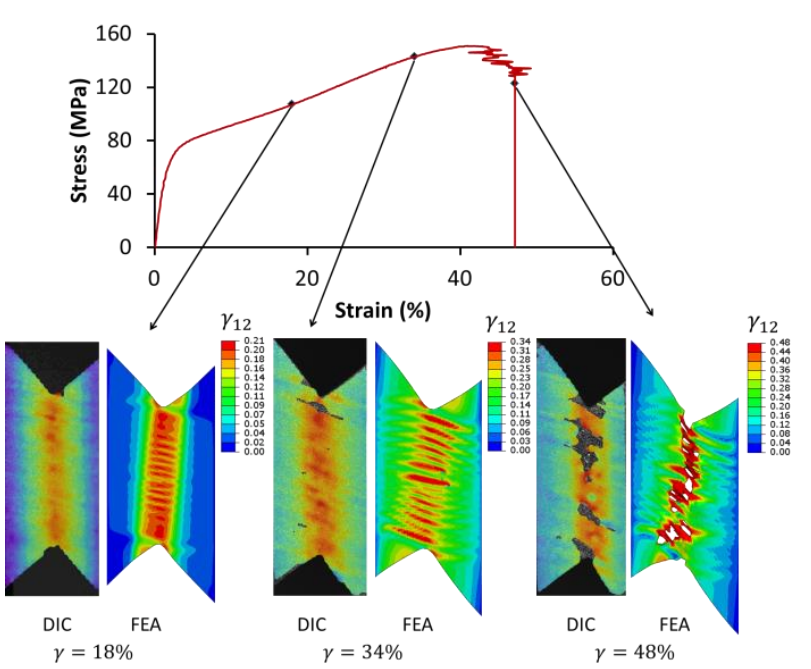

(a) Strain field
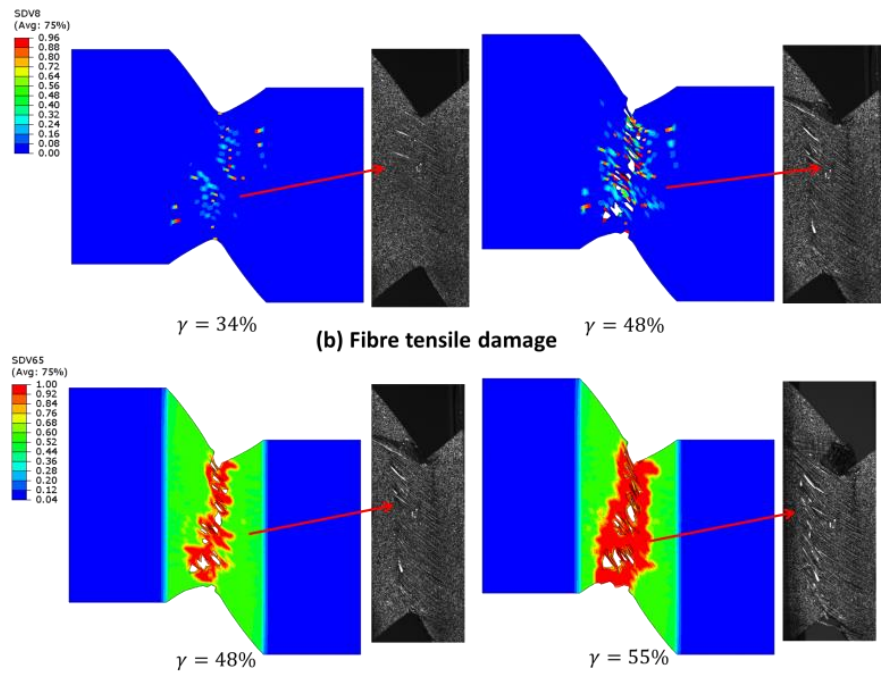

(c) Matrix damage

Fig. 19. (a) Strain contour of DIC and FEA ; (b) Fibre tensile contours and (c) matrix damage contours of V-0/90 specimens

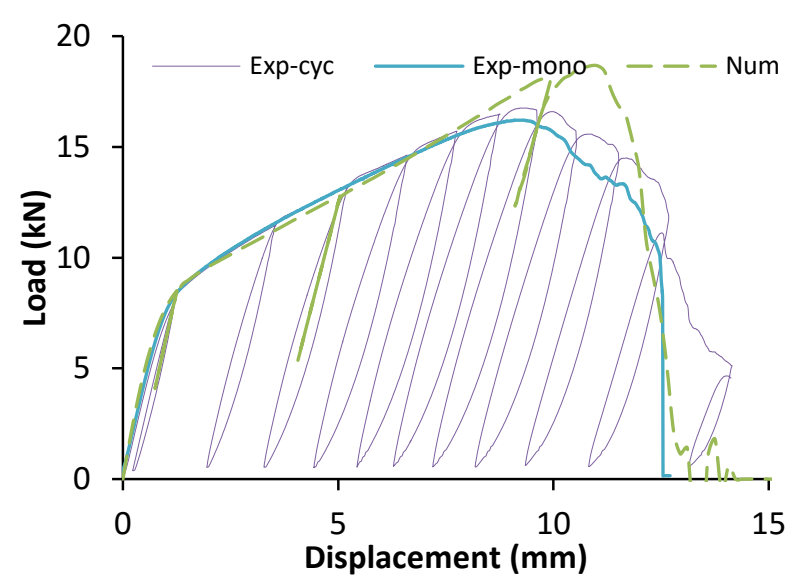


Table 1. Tested specimens $\mathrm{V}-0 / 90$ average geometries and results

\begin{tabular}{ccccc}
\hline Specimen Label & $\boldsymbol{L}(\boldsymbol{m m})$ & $\boldsymbol{t}(\boldsymbol{m m})$ & Failure load $(\boldsymbol{k N})$ & Stress $(\boldsymbol{M P a})$ \\
\hline V03 & 9.72 & 1.161 & 3.99 & 353.87 \\
V05 & 15.84 & 1.159 & 6.48 & 352.66 \\
V06 & 18.94 & 1.163 & 8.11 & 368.68 \\
V07 & 22.12 & 1.158 & 8.85 & 344.91 \\
V09 & 27.84 & 1.162 & 11.37 & 352.07 \\
V10 & 31.60 & 1.160 & 13.49 & 368.02 \\
\hline
\end{tabular}

Table 2. Material properties for laminate-level and ply-level model [42, 55]

\begin{tabular}{ll}
\hline \multicolumn{1}{c}{ Material Property } & \multicolumn{1}{c}{ Values } \\
\hline Elastic Properties (laminate) & $\mathrm{E}_{11}=\mathrm{E}_{22}=\mathrm{E}_{33}=75.022 \mathrm{GP} ; \mathrm{G}_{12}=\mathrm{G}_{13}=\mathrm{G}_{23}=$ \\
& $5.2 \mathrm{GPa} ; \mathrm{v}_{12}=\mathrm{v}_{13}=\mathrm{v}_{23}=0.0414 ;$ \\
\cline { 2 - 2 } Elastic Properties (ply) & $\mathrm{E}_{11}=139 \mathrm{GPa} ; \mathrm{E}_{22}=\mathrm{E}_{32}=10.3 \mathrm{GPa} ; \mathrm{G}_{23}=5.2 \mathrm{GPa} ;$ \\
& $\mathrm{G}_{12}=\mathrm{G}_{13}=5.2 \mathrm{GPa} ; \mathrm{v}_{12}=\mathrm{v}_{13}=0.3 ; \mathrm{v}_{23}=0.3$ \\
\hline \multirow{2}{*}{ Strength } & $X^{T}=2463 \mathrm{MPa} ; \mathrm{X}^{\mathrm{C}}=1493 \mathrm{MPa} ; \mathrm{Y}^{T}=102 \mathrm{MPa} ;$ \\
& $Y^{\mathrm{C}}=254 \mathrm{MPa} ; \mathrm{S}_{12}=\mathrm{S}_{13}=80.81 \mathrm{MPa}$ \\
\hline \multirow{2}{*}{ Fracture toughness (ply) } & $\Gamma_{11}^{\mathrm{T}}=243.9 \mathrm{~kJ} / \mathrm{m}^{2} ; \Gamma_{11}^{\mathrm{C}}=108.3 \mathrm{~kJ} / \mathrm{m}^{2} ; \Gamma_{22}^{\mathrm{T}}=$ \\
& $1.564 \mathrm{~kJ} / \mathrm{m}^{2} ; \Gamma_{22}^{\mathrm{C}}=34.58 \mathrm{~kJ} / \mathrm{m}^{2} ; \Gamma_{12}=\Gamma_{23}=\Gamma_{13}=$ \\
\hline Shear coefficients (laminate) & $34.58 \mathrm{~kJ} / \mathrm{m}^{2} ;$ \\
\hline Shear coefficients (ply) & $\tau_{i j}^{Y}=80.81 \mathrm{MPa} ; \alpha=1.6 ; \beta=-66.34 ;$ \\
\hline Degraded modulus coefficients & $\tau_{i j}^{Y}=80.81 \mathrm{MPa} ; \alpha=0.16 ; \beta=-66.34 ;$ \\
\hline Interface properties (laminate) & $p_{1}=2405 ; \mathrm{p}_{2}=-32.59 ; p_{3}=2596 ; p_{4}=-0.1764$ \\
& $\tau_{1}^{0}=61 \mathrm{MPa} ; \tau_{2(3)}^{0}=68.4 \mathrm{MPa} ; \mathrm{k}=1 \times 10^{5} \mathrm{~N} / \mathrm{mm}^{3} ;$ \\
Interface properties (ply) & $G_{I I c}=576.62 \mathrm{~kJ} / \mathrm{m}^{2}$ \\
\hline$G_{I c}=1.564 \mathrm{~kJ} / \mathrm{m}^{2} ; G_{I I c}=2.113 \mathrm{~kJ} / \mathrm{m}^{2} ; \eta=0.996 ;$ \\
& $\tau_{1}^{0}=61 \mathrm{MPa} ; \tau_{2(3)}^{0}=68.4 \mathrm{MPa} ; \mathrm{k}=1 \times 10^{5} \mathrm{~N} / \mathrm{mm}^{3}$ \\
\hline
\end{tabular}

